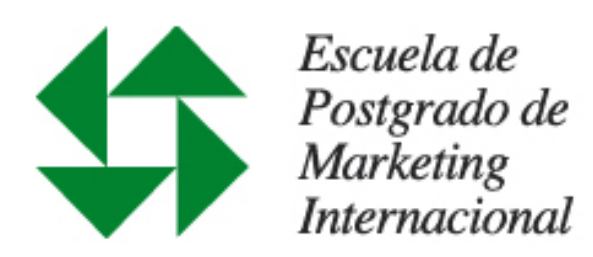

\title{
Plan de Marketing IBL para el fortalecimiento de exportaciones de tolvas graneleras en el Mercado Paraguayo
}

\author{
Trabajo Científico libre para la obtención del grado de Magister en Marketing \\ Internacional de la Escuela de Postgrado de Marketing Internacional -Facultad de \\ ciencias Económicas - Universidad Nacional de La Plata
}

Profesor Director de Tesis:

Prof. Dr. Ing. José Antonio París
Presentado por:

Ing. Clodovil Antonio Borghetti

Fecha de entrega: 30 de Junio de 2.015. 


\section{DEDICACIÓN}

Dedico este trabajo a toda mi familia, por todo el apoyo y la comprensión de todo el tiempo que he estado lejos de la comodidad del hogar a favor de los estudios. Desde el principio sabía que podía contar con todos ustedes y ustedes saben la confianza en mi capacidad.

Los profesores que, desde el inicio hasta la finalización del curso fueron capaces de transmitir ese conocimiento con amor, dedicación y entusiasmo. 


\section{AGRADECIMIENTOS}

Para Dios, el don de la vida y la protección constante.

Mi esposa Liane y mis hijas Sophia, Nicoly y Isabelli por el amor incondicional, el apoyo, la paciencia y la comprensión de la verdadera razón de los largos períodos de ausencia y viajes en favor de los estudios. Mi madre Olga, la hermana Verónica y mi hermano Giacomo por la fuerza, la amistad y la confianza. Saber que mis logros son suyas. Gracias por todo. Amo todos.

A la UNLP, sus empleados y maestros, por la calidad de la educación que recibí.

Las personas especiales que conocí en la UNLP, que más que colegas se han convertido en grandes amigos para toda la vida. $Y$ lo hicieron durante este periodo el curso vale la pena. Gracias por vuestra presencia, apoyo y compañía de siempre.

Para todos mis amigos, que de una manera $u$ otra son importantes en esta etapa de mi vida

Los profesores que han tenido que superar las barreras lingüísticas y costumbres para transmitir todas las enseñanzas con amor y dedicación.

Por fin, la empresa IBL, la oportunidad única de aprendizaje y por creer en mi trabajo. Especialmente el director Roberto Busse por su dedicación, compromiso y confianza en mi persona. 


\section{INDICE}

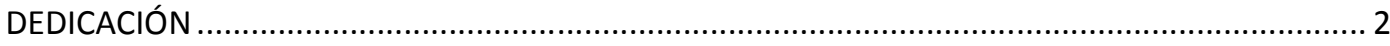

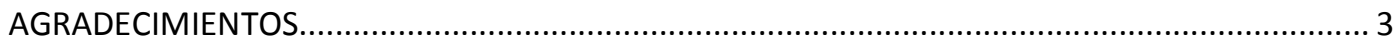

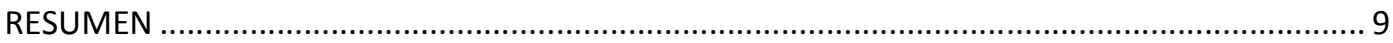

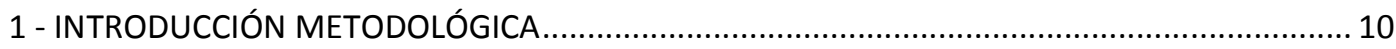

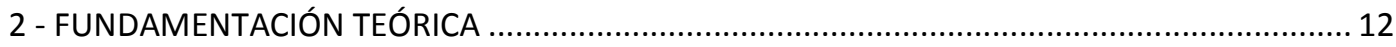

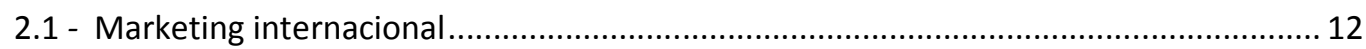

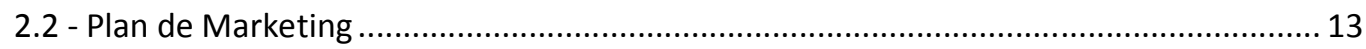

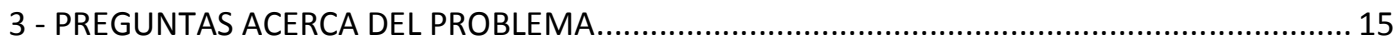

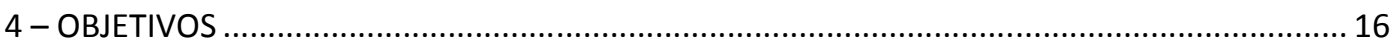

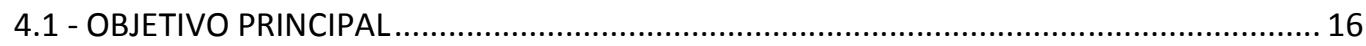

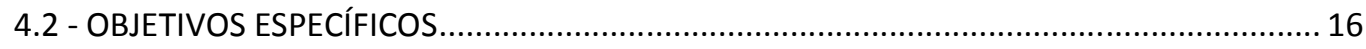

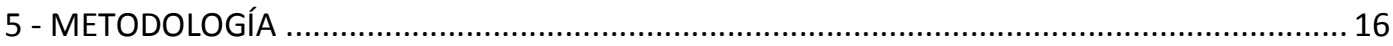

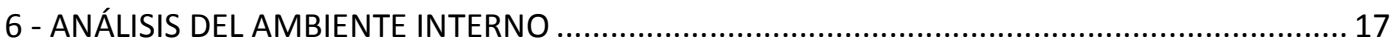

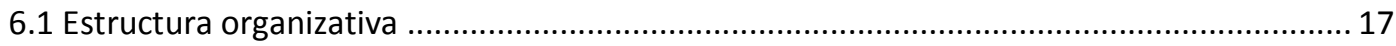

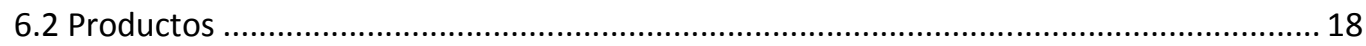

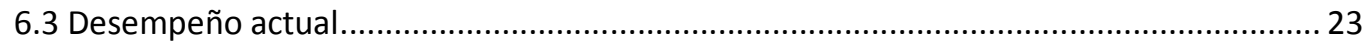

6.4 Metas para ampliación del mercado externo ..................................................... 25

7 - ANÁLISIS DEL AMBIENTE EXTERNO (Información ofrecida por la empresa IBL)................... 26

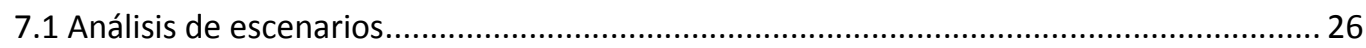

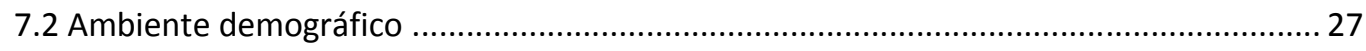

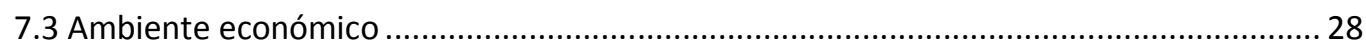

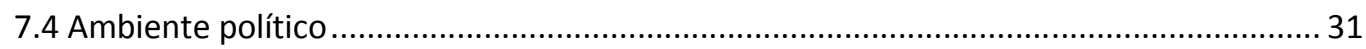

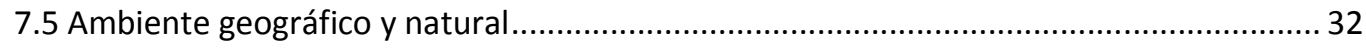

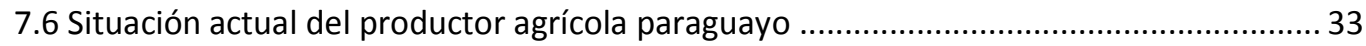

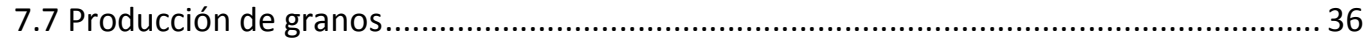

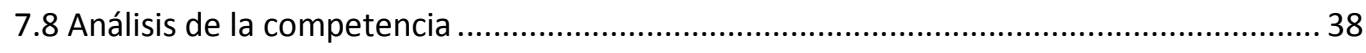

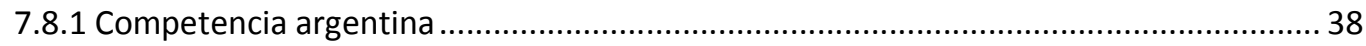

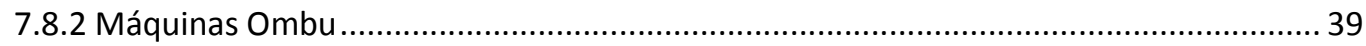

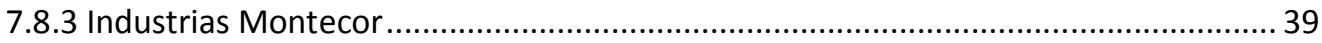

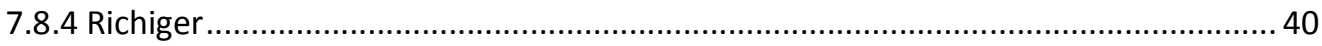

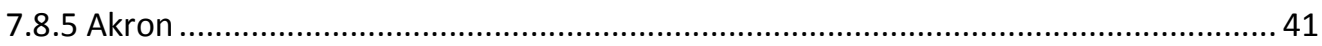

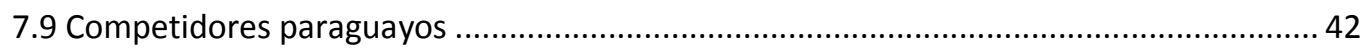




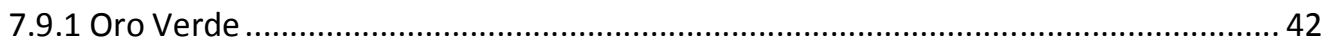

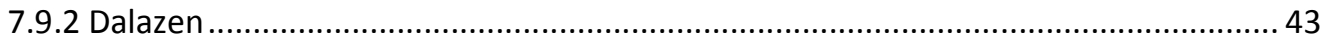

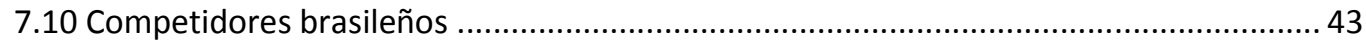

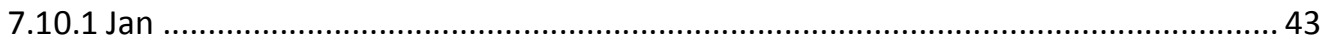

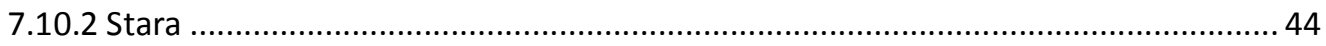

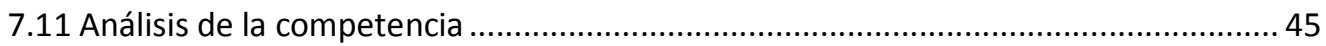

8 - ANÁLISIS SWOT (Strengths, Weaknesses, Opportunities and Threats) (FODA Fortalezas,

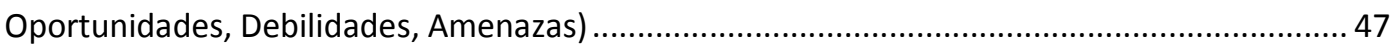

9 - ANALISIS ARCO (Aspiraciones de los líderes, Restriciones ambientales, Capacidades de la

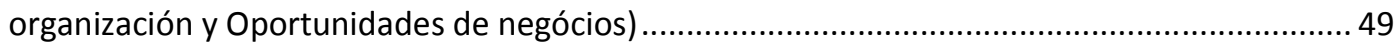

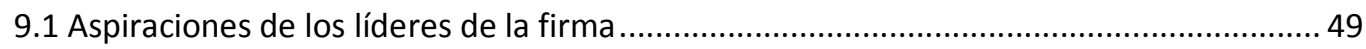

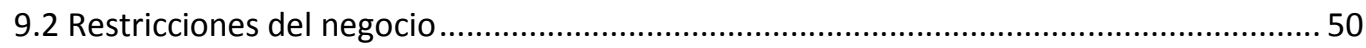

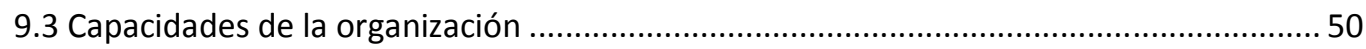

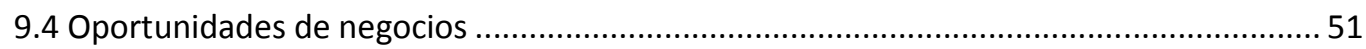

10 - SEGMENTACIÓN, POSICIONAMIENTO Y OBJETIVOS DE MARKETING ...................................51

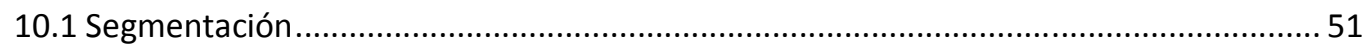

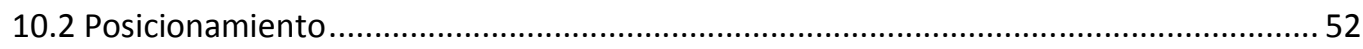

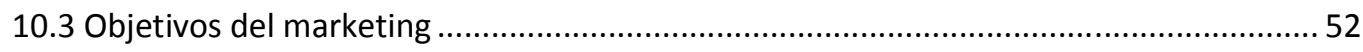

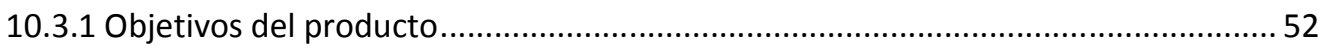

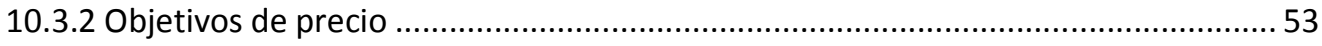

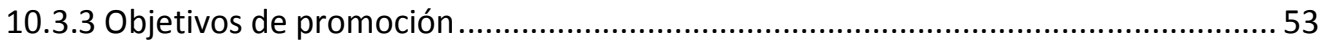

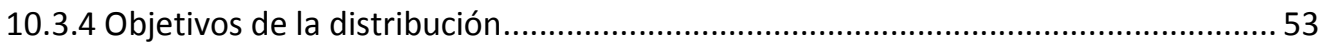

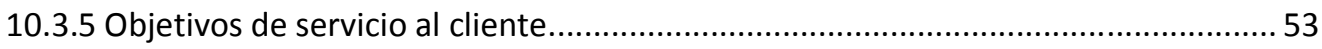

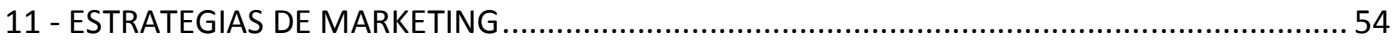

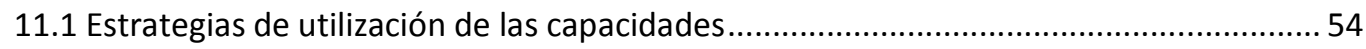

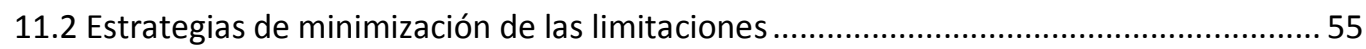

11.3 Estrategias de conversión de las desventajas ............................................................... 56

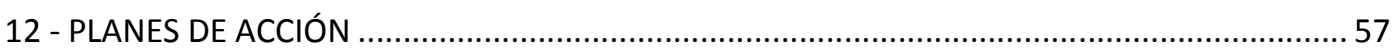

12.1 Plan de acción 1 - Aumento de la actuación de la marca IBL en Paraguay ..................... 57

12.2 Plan de acción 2 - Enfoque en la divulgación del modelo ABA 12.500 Multiuso .............58

12.3 Plan de acción 3 - Encuesta de perfil y nivel de satisfacción con la IBL ...........................59

12.4 Plan de acción 4 - Análisis periódica de la competencia ..................................................6 60

12.5 Plan de acción 5-Ajustar los medios de comunicación para el mercado objetivo .........61 61

12.6 Plan de acción 6 - Cualificación de proveedores ........................................................... 61

12.7 Plan de acción 7 -Optimización del proceso de producción ........................................... 62 


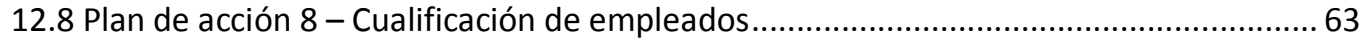

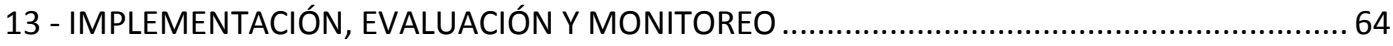

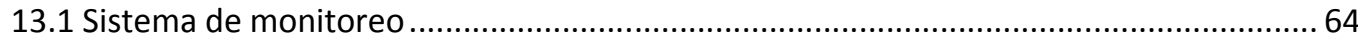

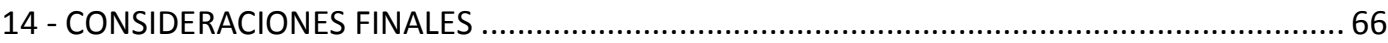

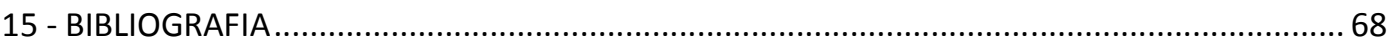

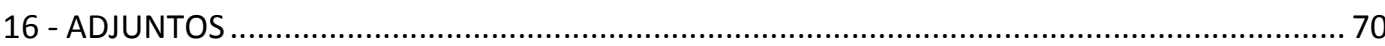




\section{LISTA DE ILUSTRACIONES}

Cuadro $1 \quad$ Principales productos IBL............................... 20

Cuadro 2 Comparativo de tolvas IBL........................... 22

Tabla $1 \quad$ Exportación total $\mathrm{X}$ exportación de tolvas...................... 23

Grafico $1 \quad$ Exportación total X exportación de tolvas..................... 23

Tabla $2 \quad$ Unidades de tolvas exportadas para Paraguay................... 23

Tabla $3 \quad$ Total exportaciones del Brasil en $2008-2012 \ldots \ldots \ldots \ldots \ldots . . \ldots$

Tabla $4 \quad$ Facturación IBL X exportaciones............................ 26

Grafico $2 \quad$ Facturación IBL X exportaciones............................ 26

Tabla $5 \quad$ Balanza comercial Paraguay $2008-2012 \ldots \ldots \ldots \ldots \ldots \ldots \ldots \ldots \ldots \ldots$

Cuadro $3 \quad$ Principales países exportadores e importadores.............. 32

Cuadro $4 \quad$ Balanza comercial entre Brasil x Paraguay.................. 33

Gráfico 3 Comparativo da balanza comercial Brasil X Paraguay 34

Figura $1 \quad$ Mapa de límites de frontera do Paraguay.......................... 36

Gráfico $4 \quad$ Evolución de la producción de soja en el Paraguay........... 40

Grafico $5 \quad$ Evolución de la producción de maíz en el Paraguay........... 40

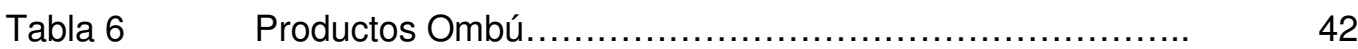

Tabla $7 \quad$ Productos Montecor ..................................... 43

Tabla $8 \quad$ Productos Richiger...................................... 44

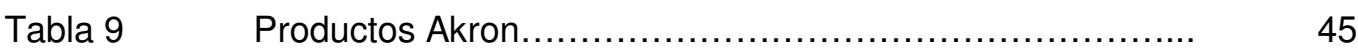

Tabla $10 \quad$ Productos Oro Verde ..................................... 46

Tabla $11 \quad$ Productos Dalazen...................................... 46

Tabla $12 \quad$ Productos Jan................................................. 47

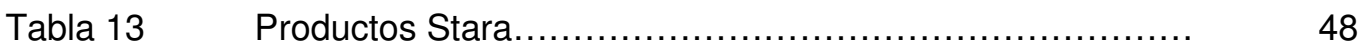

Cuadro $5 \quad$ Evaluación de los puntos fuertes............................ 51

Cuadro $6 \quad$ Evaluación de los puntos débiles............................ 52

Cuadro $7 \quad$ Oportunidades encontradas.............................. 52 
Cuadro $8 \quad$ Amenazas enfrentadas.................................... 53

Cuadro $9 \quad$ Oportunidades + puntos fuertes $=$ Estrategias $\ldots \ldots \ldots \ldots \ldots \ldots . \ldots$

Cuadro 10 Oportunidades + puntos flacos $=$ Estrategia $\ldots \ldots \ldots \ldots \ldots \ldots . . \ldots$

Cuadro $11 \quad$ Amenazas + puntos flacos $=$ Estrategias $\ldots \ldots \ldots \ldots \ldots \ldots \ldots \ldots \ldots \ldots$

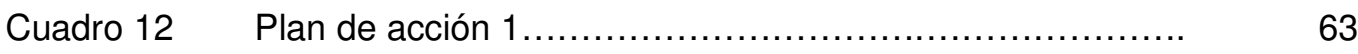

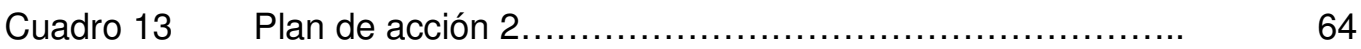

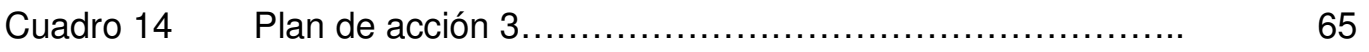

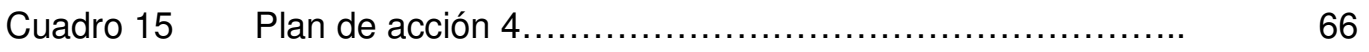

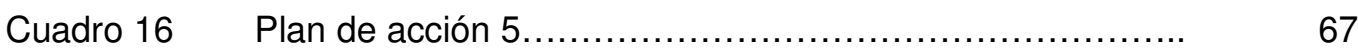

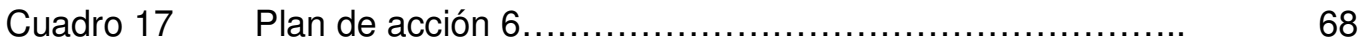

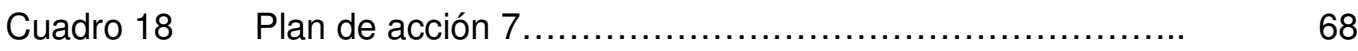

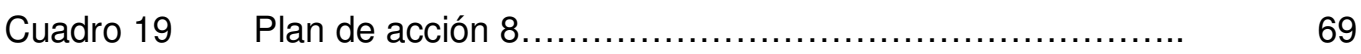

Cuadro $20 \quad$ Sistema de monitoreo.................................. 71 


\section{RESUMEN}

La evidente intensificación de las relaciones comerciales entre los países obligan a las empresas, cada vez, más a ampliar sus mercados a nivel internacional. Por tanto se necesitan estrategias de comercio exterior claras y objetivas. En el mercado de la maquinaria agrícola e implementos el Brasil es un candidato natural para ser uno de los productores más grandes del mundo por reunir las condiciones esenciales de la competitividad: la tecnología, materias primas, mano de obra, la experiencia acumulada, potencial de mercado, etc. Sin embargo, varios aspectos, tanto sistémicos y específicos, pueden llegar a ser restrictiva para el ingreso de productos brasileños en este sector en el extranjero.

Este trabajo se centra en la creación de un plan de marketing internacional, dirigido específicamente hacia el mercado paraguayo para la empresa Industrial Busse Maquinas e Implementos Agrícolas Ltda. (IBL). Se buscará identificar las estrategias de marketing más adecuadas a la situación actual de la empresa y el mercado, y crear planes de acción coherentes con las orientaciones estratégicas.

Palabras clave: comercio exterior, la exportación, plan de marketing internacional 


\section{1 - INTRODUCCIÓN METODOLÓGICA}

Es notable el crecimiento del mercado agrícola brasileño, que se ha mostrado en los últimos años. La industria está pasando por una fase muy positiva: buen precio, créditos accesibles a los consumidores, alta productividad y tasas estables y aceptables de productos en el exterior.

Sin embargo, este sector se caracteriza por fluctuaciones profundas en los niveles de producción, hay muchos factores que influyen, como: clima, tipo de cambio y los precios desfavorables como ocurrió a finales de 2008 y 2009, y la conocida "crisis global", que alcanzó varios productores y desencadenó una serie de medidas por parte del gobierno.

A pesar de todas las adversidades, sabemos que Brasil es un gran productor de granos / alimentos a consecuencia de poseer grandes extensiones de tierra, clima favorable y lluvias regulares. Este progreso no es diferente al de la maquinaria agrícola que promueve los avances hacia un desarrollo cada vez mayor. El Brasil posee mano de obra calificada, tecnología avanzada y una amplia experiencia en el negocio.

La industria de la maquinaria agrícola es un importante generador de empleo e ingresos para el país. Las empresas pequeñas, medianas y grandes son responsables del consumo de grandes cantidades de placas de acero, tornillos, perfiles de acero especiales, productos químicos, plásticos, caucho y otras materias primas e insumos.

La situación de las empresas de implementos agrícolas y maquinaria es directamente proporcional al desempeño de la agricultura en el país. Siendo así, si la cosecha es buena, el productor puede aprovechar e invertir más en su negocio, el dinero empieza a circular, la mayoría de las empresas comienzan a emerger y los fabricantes de maquinaria pueden producir con una mayor eficiencia y seguridad. Por otro lado si el cultivo no alcanza niveles aceptables, el país puede pasar del éxito al inicio de una recesión.

Frente a estas situaciones impredecibles, las empresas tratan de diversas maniobras para no correr el riesgo de una crisis y asegurar su supervivencia. En este punto entra en juego el enfoque de la internacionalización, que sirve como una clave alternativa para ayudar en el mantenimiento de la organización de ingresos y de negocios. Sobre todo la internacionalización y la profundización de los negocios internacionales se deben realizar en los períodos de auge como el que se está viviendo en la actualidad. 
Con esta decisión, las inversiones de la empresa en otro universo, se encuentran con una serie de desafíos. Para ser competitiva en los mercados extranjeros necesita desarrollar estrategias para lograr sus objetivos. Queda mucho por hacer y solo hay espacio para personas comprometidas, del análisis de la escena internacional a una serie de estudios y análisis y el éxito fruto del esfuerzo y la competencia de las personas que están a cargo de los proyectos.

Este trabajo se propone estudiar el comportamiento de la corriente Industrial Busse Máquinas e Implementos Agrícolas Ltda. (nombrado IBL) en el mercado paraguayo y desarrollar un plan de marketing para aumentar la competitividad de la empresa a su lado. 


\section{2 - FUNDAMENTACIÓN TEÓRICA}

Según López (2005) ${ }^{1}$ es una estrategia alternativa al desarrollo de las exportaciones, ya que promueve la eficiencia. El aumento de la competitividad provoca la aparición de bienes y servicios cada vez mejores, con el fin de adaptar el producto al mercado extranjero. Esto termina por producir un cambio de mentalidad que ofrece un salto cualitativo y cuantitativo, con efectos positivos, también sobre su desempeño en el mercado interno.

Según Minervini (2005) ${ }^{2}$ las empresas tienen que exportar por varias razones, entre ellas: la estrategia de desarrollo, por el mejor uso de las instalaciones, la necesidad de trabajar con mayores volúmenes de producción, la capacidad de subir los precios, y así hacer más rentable el ciclo de vida de los productos y mejorar la imagen de la empresa. Aunque el autor afirma que otra de las ventajas es separarse con otras realidades, de otros competidores y con otros requisitos. Todo esto lleva a la empresa a ser más competitiva.

Otro autor que habla muy bien de las exportaciones es Aleksink (2012) ${ }^{3}$ cuando afirma que las exportaciones son un recurso en un país en tiempos difíciles. Muchas empresas comienzan esporádicamente y luego se consolida.

\section{1 - Marketing internacional}

Hay varias formas de entender el marketing, cuando se trata de organizaciones se debe entender cuáles son las necesidades y deseos de los clientes a través de la creación de beneficios para éstos.

López (2005) ${ }^{4}$ pone de relieve que el concepto de marketing se puede entender mejor cuando se compara con el concepto de venta. Si bien el concepto de venta se inicia en la fábrica, se centra en productos de la compañía y pone de relieve la ganancia por venta, la comercialización comienza con el mercado, se centra en las necesidades del cliente y hace hincapié en el beneficio y la satisfacción del cliente.

Cuando hablamos de marketing internacional, se puede decir que siguen la misma lógica del mercado interno, pero los esfuerzos hacia los mercados extranjeros requieren una visión más global, que incluye aspectos culturales, retos, incertidumbres

${ }^{1}$ LOPEZ, José Manoel Cortiñas. (2005). Comércio exterior competitivo. 2. ed. São Paulo: Lex Editora.

${ }^{2}$ MINERVINI, Nicola. (2005). O exportador. 4. Ed. São Paulo: Pearson Prentice Hall.

${ }^{3}$ ALEKSINK, Néstor e SERGE, Gustavo. (2012). Fundamentos para um proyecto de exportación. 2. ed. Osmar D.

BuyattiLibreria Editorial. Buenos Aires.

${ }^{4}$ LOPEZ, José Manoel Cortiñas. (2005). Comércio exterior competitivo. 2. ed. São Paulo: Lex Editora. 
y realidades diferentes. López (2005) retrata a éste cuando se hace referencia al hecho de que la comercialización internacional puede ser definida como el logro de las actividades empresariales dirigidas a bienes y servicios en el extranjero con fines de lucro para la satisfacción de las necesidades y deseos de los clientes. El autor también escribe que las herramientas de marketing internacional son básicamente las misma que en el mercado interno, lo que varía es la forma de aplicación, teniendo en cuenta las variables del mercado interno.

Desde el punto de vista de Días (2004), la práctica del marketing de forma contínua y competente, dando lugar a un sólido crecimiento de las ganancias de la empresa porque genera ingresos, que es administrado por las finanzas personales. También, de acuerdo con el autor, para aumentar las ventas y los ingresos, marketing ayuda a cubrir los costos fijos de la empresa, aumentando así su rentabilidad.

\section{2 - Plan de Marketing}

Cada vez que se piensa acerca de cómo iniciar un negocio, ya sea inicial o de expansión, siempre debe haber un estudio de varios factores y variables intervinientes. Este trabajo consiste en reducir al mínimo los riesgos y llevar a la empresa a alcanzar el ansiado éxito. Sin embargo muchas empresas parecen ignorar este paso y ni siquiera se proponen definir la meta.

Según Ferrell y Hartline (2005)5, el plan de marketing es un proyecto diseñado para apuntar a la empresa en su situación actual en el mercado, identificar oportunidades de mercado y orientar la formulación de un plan capaz de organizar las actividades de la empresa para lograr sus objetivos estratégicos.

El mismo autor también afirma que la aplicación de un plan de marketing es fundamental para el éxito de cualquier empresa, ya que es responsable de la aplicación de la estrategia de marketing.

Las empresas centradas en un mayor rendimiento de sus objetivos, buscan dirigir su marketing a través de un plan de marketing. Según Kotler y Keller (2006) ${ }^{6}$ el plan de marketing es una de las acciones de marketing centralizados en empresas. Se utiliza para establecer los objetivos, las oportunidades, la propuesta de valor, promociones, canales de ventas y servicios. El mismo autor también se refiere a la existencia de dos niveles en el plan de marketing: estratégico y táctico.

${ }^{5}$ FERRELL, OC; HARTLINE, M. D. (2005). Estratégia de marketing. São Paulo: Pioneira Thomson Learning.

${ }^{6}$ KOTLER, Philip e KELLER Kevin Lane.(2006). Administração de marketing.Pearson Prentice Hall .São Paulo. 
Además de preocuparse por la comercialización, las empresas deben prestar atención al proceso administrativo. Según Kotler y Armstrong $(2007)^{7}$ debe contar con planes estratégicos, más generales y que luego se traducen en planes de marketing.

Siguiendo la idea de la planificación estratégica como parte del proceso administrativo, se puede seguir la idea Chiavenato y Sapiro $(2010)^{8}$ se coloca en la mira a la planificación estratégica como algo que implica al grueso de la organización. Siempre siguiendo la idea de los autores, este plan de marketing insertado en la planificación estratégica desarrolla acciones como: diseño de investigación, plan de ventas, plan de publicidad, plan, estrategias de marketing y el plan de distribución.

${ }^{7}$ KOTLER, Philip e ARMSTRONG Gary.(2007) Princípios de marketing. Pearson Prentice Hall .São Paulo. ${ }^{8}$ CHIAVENATO, Idalberto e SAPIRO, Arão. (2010). Planejamento estratégico, Fundamentos e aplicações. Ed. Campus. Rio de Janeiro. 


\section{3 - PREGUNTAS ACERCA DEL PROBLEMA}

¿Cuáles son los factores ambientales internos y externos que afectan a la empresa IBL?

Frente a un análisis SWOT (Strengths, Weaknesses, Opportunities and Threats) (FODA Fortalezas, Oportunidades, Debilidades, Amenazas), ¿cuáles son las estrategias de marketing y los objetivos que la empresa debe tomar?

¿Cómo un plan de marketing combina las herramientas de comunicación y otros elementos de marketing del compuesto para coordinar las acciones de la empresa? 


\section{4 - OBJETIVOS}

\section{1 - OBJETIVO PRINCIPAL}

Desarrollar un plan de marketing para fortalecer la exportación de Tolvas IBL para el mercado paraguayo.

\section{2 - OBJETIVOS ESPECÍFICOS}

Llevar a cabo un análisis ambiental que implica factores internos y externos que afectan a la empresa.

Desarrollar un análisis SWOT (FODA) combinada con un análisis ARCO (Aspiraciones de los líderes, Restricciones ambientales, Capacidades de la organización y Oportunidades de negocios) para identificar la actual situación del productor paraguayo y, con eso, determinar que estrategias de marketing y objetivos que la empresa debe seguir para este mercado.

Llevar a cabo un programa de acción para poner las estrategias ya definidas por la empresa y determinar un sistema de monitoreo para medir la efectividad de las acciones, pudiendo alterar y dar nuevos rumbos al programa

\section{5 - METODOLOGÍA}

Para este trabajo, hemos optado por el método deductivo de estudio de caso, ya que se considera que el mismo cumple con las características diversas de esta investigación, como el hecho de que se trata fundamentalmente de un análisis cualitativo exploratorio. Se desea obtener una visión más completa del problema objeto de estudio: el hecho de que se está analizando un proceso (fenómeno en curso); análisis de numerosas variables, y la naturaleza del problema de ser apropiado utilizar el método.

Se hará un análisis ambiental de los factores internos y externos que afectan a la empresa, análisis FODA, herramientas de marketing de la empresa, estrategias y objetivos de marketing. Habrá un estudio de alcance sobre el contenido preexistente.

Con el análisis ARCO, será posible determinar la problemática del sector agropecuario paraguayo, pudiendo apuntar soluciones posibles, sistema de valores, identificación de motivadores de compra, definiendo así, metas para la empresa. 
Tendremos también que buscar información en fuentes secundarias y también se utilizará estudios previos, libros, revistas relacionados con el tema, artículos técnicos, revistas, además de internet.

El trabajo de desarrollo se basa en la idea de que escriben renombrados autores sobre el tema en cuestión. Se utilizarán las herramientas existentes para determinar cómo la empresa investigada puede avanzar sobre sus objetivos de reforzar y reemplazarse en el mercado paraguayo.

Los documentos y la información proporcionada por la empresa investigada servirán como indicadores cuantitativos. Ellos se compilarán para generar una imagen de cómo la compañía está llevando a cabo la exportación.

\section{6 - ANÁLISIS DEL AMBIENTE INTERNO}

Se presentan en esta etapa las características actuales de la empresa IBL, como: estructura, cultura organizativa, los productos, el desempeño actual, inversiones y metas de crecimiento.

\subsection{Estructura organizativa}

IBL actualmente cuenta con 120 empleados, entre administrativos y de manufactura, que a su vez, se divide en dos unidades. La compañía es un negocio familiar y gestionado por dos miembros (padre e hijo). A partir de ahí aparece una estructura de departamentos: financiero, de personal, contabilidad, compras, ventas e industrial. Cada departamento tiene su cabeza que siempre responde por la gestión.

La actividad de exportaciones está administrada por el sector de ventas, el cual cuenta con una persona que ejecuta las funciones de documentación y cambio y otra persona que realiza la función de atención a los clientes del exterior, bien como, negociación, negociación de transporte, logística, prospección de mercado, participación en ruedas de negocios, ferias, cobranzas, entre otras. No hay, pues, un sector de exportación en particular, debido a que los volúmenes de venta para el exterior no justifican la creación de uno. 
Los encargados de las ventas poseen un amplio conocimiento del producto y de los procesos productivos de las máquinas. Con eso, la empresa sabe que puede confiar en que la función de ventas al exterior será realizada correctamente.

Además de lo anterior, IBL tiene una historia de más de 30 años de relaciones comerciales con los países del MERCOSUR, durante este período muchos productos han sido desarrollados, muchas asociaciones se han creado y mucha experiencia se ha adquirido. Por medio de errores y éxitos, IBL logró destacar su marca con productos de calidad y buen precio.

\subsection{Productos}

Antes de principios de los 70, la empresa no producía implementos agrícolas, era sólo un taller de reparación de maquinaria y equipo. Este taller Busse proporcionaba servicios a los clientes en toda la región y era bien conocido. A partir de ahí, la empresa creció y se convirtió en una fundición donde tenía varios clientes. En 1972 la compañía pasa a llamarse IBL y luego comienza su trayectoria de éxito en la producción de máquinas e implementos agrícolas. Varios productos se han desarrollado, muchos, aún hoy después de las modificaciones a las que han sido sometidas son éxito de ventas.

En la actualidad, la empresa cuenta con una gran línea de productos que incluye instrumentos para la preparación y reparación de suelos, tales como arados, cubiertas traseras, podadoras, aplanadoras. También cuenta con una línea de remolques agrícolas de madera, vagones metálicos forrajeros y de elevación hidráulica, una línea de trituradoras, pero, sin duda, la línea responsable de la mayor parte de los ingresos de la empresa, es la línea de transporte y transbordo de granos que son las tolvas. Estas máquinas vienen cada año ganando más y más clientes, por lo que IBL tiene ahora una unidad de fabricación totalmente destinada a la producción de esta línea.

Cuadro1: principales productos IBL

\begin{tabular}{|c|c|}
\hline \multicolumn{2}{|c|}{ Cuadro de los principales productos IBL - Busse Agro } \\
\hline Tipo & modelo \\
\hline Acoplado Agrícola & CAM2 \\
\hline Acoplado Agrícola & CAF3 \\
\hline
\end{tabular}




\begin{tabular}{|c|c|}
\hline Acoplado Agrícola & CAB3 \\
\hline Acoplado Agrícola & CATB4 \\
\hline Acoplado Agrícola & CA6 \\
\hline Acoplado Agrícola & CA7 \\
\hline Acoplado Agrícola & CAT 8 \\
\hline Acoplado forrajero hidráulica & CFH 4700 \\
\hline Acoplado forrajero hidráulica & CFH 6000 \\
\hline Acoplado forrajero hidráulica & CFH 7000 \\
\hline Acoplado forrajero hidráulica & CFH 9000 \\
\hline Tolva arrocera & AR90 \\
\hline Tolva arrocera & AR100 \\
\hline Tolva arrocera & AR130 \\
\hline Tolva arrocera & AR150 \\
\hline Tolva multigranos & Granera 140 \\
\hline Tolva multigranos & Super Granera 170 \\
\hline Tolva multigranos & Super Granera 200 \\
\hline Tolvaabastecedora & ABA 12500 \\
\hline Tolvaestacionária & SGE 261 \\
\hline Palita tracera & SGE 311 \\
\hline Palita tracera & $P 1500-P 2000-P 2400$ \\
\hline Plataforma tracera & RT1300 - RT1600 - RT2000 \\
\hline Desmalezadera de suelo & R1300 - R1600 - R1800 \\
\hline Molino de cereales & M 24 \\
\hline Molino de cereales & M 48 \\
\hline
\end{tabular}

Fuente: IBL - 2013

Con la experiencia adquirida durante todos los años en que IBL ha estado en el mercado, ha sido posible mantener una gran cantidad de clientes, muchos no cambian la marca IBL por ninguna otra y siempre recomiendan los productos de esta marca. IBL se centra en satisfacer las necesidades de los agricultores, realmente desarrolla productos que satisfacen las necesidades que tenga el cliente, gran parte del éxito de la empresa se encuentra en este punto.

La conservación ambiental y la preocupación por las nuevas generaciones también son razones de acciones en la empresa. Así que los productos se fabrican con tecnología limpia totalmente dentro de los estándares ambientales requeridos por 
los órganos competentes. El cliente puede estar seguro de que está adquiriendo un producto que fue producido sin dañar el medio ambiente.

Para este estudio, nos centraremos en las tolvas. Esta línea ha sido objeto de las mayores inversiones de IBL en los últimos años. Muchos estudios y pruebas se han hecho para conseguir los productos de calidad que se producen hoy en día en la empresa.

Con el creciente desarrollo de la agricultura en su conjunto, el enfoque de los agricultores es el alto rendimiento en tiempo de cosecha. En este punto las tolvas juegan un rol importante, que realizan la función de transbordo de los granos de la cosechadora a un camión $u$ otro medio de transporte que no puede entrar en el campo. Así, la cosechadora no necesita estar parada para pasar al lado de la carretera para vaciar su reservorio.

IBL tiene actualmente dos marcas, una de ellas la propia IBL y la otra Busse Agro, ambas marcas tienen tolvas. La marca Busse Agro se destaca por las tolvas especiales de arroz, pero se ha probado y se puede utilizar con diversos granos como la soja y el maíz. Ahora hay cuatro modelos de tolvas de arroz: AR-90, AR-100, AR130, y AR-150. Estas máquinas tienen un diseño cónico que permite un mejor flujo de arroz con cáscara dentro de la máquina. También tiene componentes de acero con un tratamiento especial para evitar la corrosión. Desde que comenzó la producción de arroz se hicieron muchos cambios, todo pensando en el bienestar y agilidad del trabajo del agricultor. Además de la mayor capacidad de carga, mejoraron otros elementos de ingeniería como la tubería de descarga, caja de cambios, cambios estructurales. Con todas estas adaptaciones esta máquina es ahora muy bien aceptada por los clientes. Las principales regiones compradoras de arroz son los estados del sur de Brasil, una región que produce alrededor del $80 \%$ de arroz en Brasil.

La marca IBL está grabada en las tolvas modelo Granera y silos estacionarios. La línea Graneras actualmente tiene tres modelos: el Granera 140, Super Granera 170 y Super Granera 200. Con esta variedad de modelos con diferentes capacidades se puede satisfacer mejor a diversas necesidades. Del mismo modo que las tolvas de arroz, la línea Graneras también se ha mejorado desde su inicio y también ha sido fabricada en una planta específica para la producción de estas máquinas. 
Cuadro2: Tabla comparativa de tolvas IBL

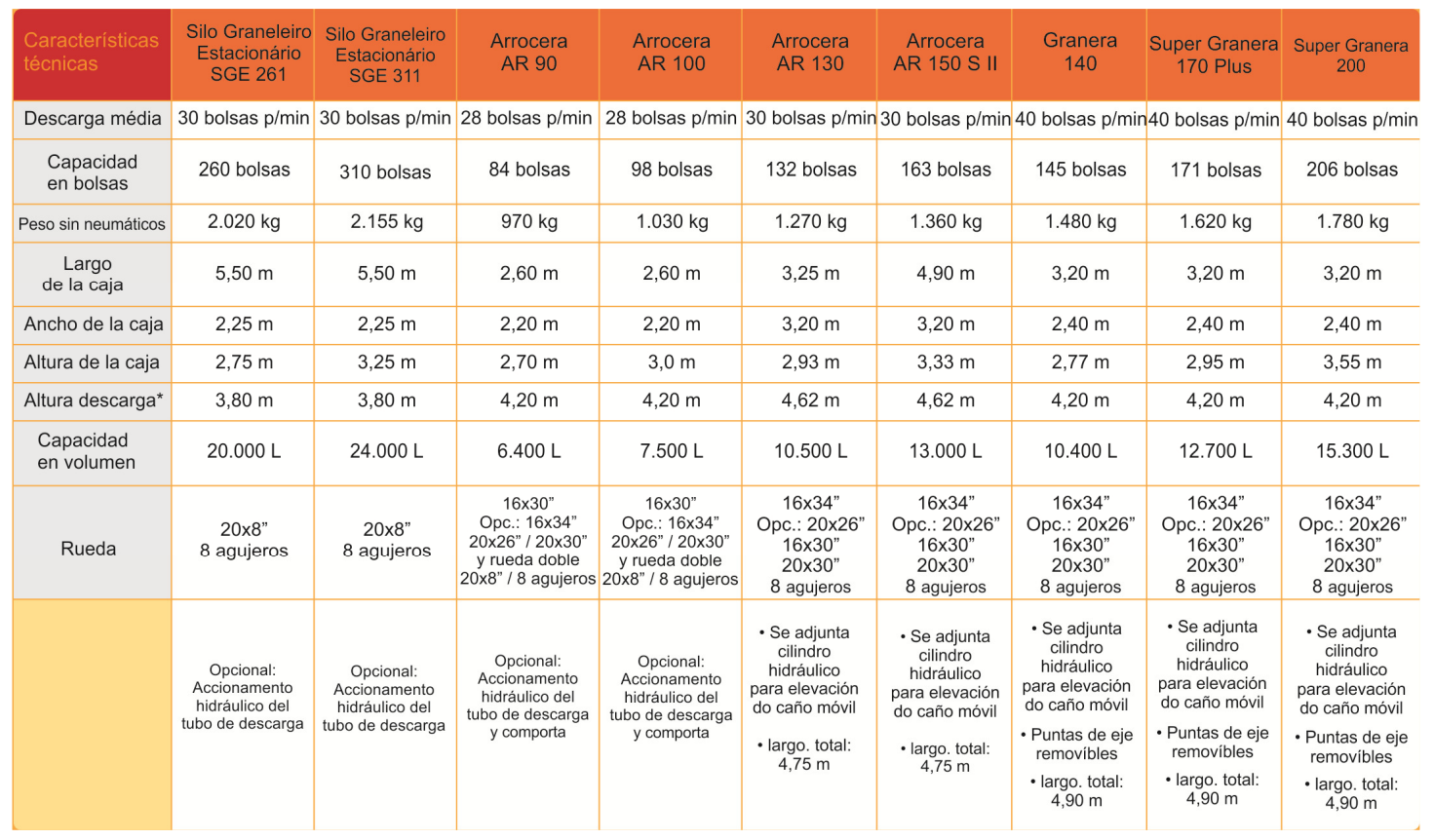

Fuente: IBL

A pesar de tener productos de calidad y buen precio, la venta de tolvas para el mercado objetivo de este plan de marketing, Paraguay, sigue siendo tímida como se puede observar en la siguiente tabla:

Tabla 1: Exportación total $x$ exportación de tolvas

\begin{tabular}{|c|c|c|c|c|c|}
\hline \multicolumn{6}{|c|}{ Exportación total x Exportación de Tolvas } \\
\hline & $\mathbf{2 0 0 8}$ & $\mathbf{2 0 0 9}$ & $\mathbf{2 0 1 0}$ & $\mathbf{2 0 1 1}$ & $\mathbf{2 0 1 2}$ \\
\hline Total & 138.254 & 67.528 & 105.239 & 118.323 & 145.177 \\
\hline Tolvas & 44.241 & 0 & 9.471 & 87.536 & 27.583 \\
\hline Porcentaje & $32 \%$ & $0 \%$ & $9 \%$ & $73 \%$ & $19 \%$ \\
\hline
\end{tabular}

Fuente: IBL - 2013

Gráfico 1: Exportación total x exportación de tolvas

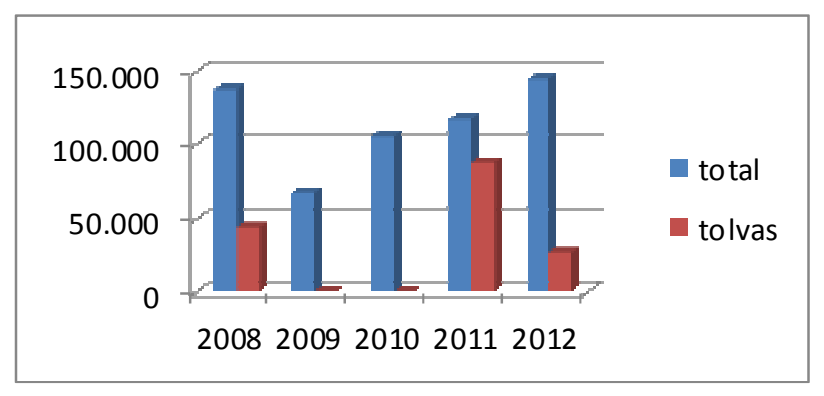

Fuente: IBL -2013 
En unidades exportadas podemos llegar a los siguientes datos:

Tabla 2: Unidades de tolvas exportadas para el Paraguay

\begin{tabular}{|c|c|c|c|c|c|}
\hline \multicolumn{7}{|c|}{ Unidades de tolvas exportadas al Paraguay } \\
\hline \multicolumn{7}{|c|}{ Unidades } \\
\hline & $\mathbf{2 0 0 8}$ & $\mathbf{2 0 0 9}$ & $\mathbf{2 0 1 0}$ & $\mathbf{2 0 1 1}$ & $\mathbf{2 0 1 2}$ \\
\hline Total & 20 & 0 & 5 & 24 & 14 \\
\hline
\end{tabular}

Fuente: IBL - 2013

Haciendo un análisis del panorama vivido por IBL en los últimos cinco años, se observa que hay mucha variación en cuanto a los valores y las cantidades exportadas. Se llega a los picos de 24 unidades y caídas de 0 (cero) unidades. En conversación con los directores responsables de la empresa se puede ver que no hay una política específica para la promoción de productos en los mercados extranjeros, la empresa vende básicamente cuando los clientes solicitan cotización, es decir, contactan la compañía. No se hace un esfuerzo para promover acciones en el extranjero. Mucho de esto ocurre porque IBL tiene un mercado interno muy acalorado, y direcciona todos sus esfuerzos de producción para satisfacer este mercado.

Se espera una evolución más amplia en las ventas de tolvas porque el socio comercial de IBL abrió una sucursal en la ciudad de Santa Rita(Paraguay), una región que es el mayor productor de granos (principalmente maíz y soja) de ese país. La región de Santa Rita concentra un alto porcentaje de brasileños y muchos ya conocen la marca y la calidad de los productos IBL, este hecho contribuyó para el apalancamiento de las ventas.

IBL tiene como objetivo incrementar gradualmente sus ventas, siempre de una manera segura y competente. Por lo tanto el buque insignia será el "Super Granera 170" porque es el producto que ha sido más aceptado y es el más grande de la línea. Con el tiempo la idea es la inclusión de nuevos productos también en la línea de tolvas. 


\subsection{Desempeño actual}

Según Secex (Secretaría de comercio exterior de Brasil), en los últimos años es notable el crecimiento que Brasil ha tenido en sus exportaciones. Cada vez más empresas están haciendo negocios con el exterior. Esto hace con que el país tenga una gran entrada de divisas que contribuye a la fuerza de la nación. El hecho que ocurre es que el elevado número de exportaciones es generado por la venta de productos primarios con poco o ningún valor añadido.

La misma fuente afirma que en 2012, Brasil tuvo un superávit de US\$19.432 mil millones, con un valor de las exportaciones de aproximadamente US\$242.579 mil millones. Estos valores, aunque altos, están abajo de los de 2011, cuando el superávit fue de US\$29.793 mil millones, con exportaciones de US\$256.039 mil millones. Se puede decir que las exportaciones brasileñas siguen las direcciones del mercado externo, con subidas y caídas. Crisis de 2009, una considerable reducción de las exportaciones, la buena cosecha y moneda estable, el aumento de 2011. Inestabilidad de la moneda, cayendo en 2012.

Tabla 3: Total de exportaciones del Brasil en 2008 a 2012

\begin{tabular}{|c|c|c|c|c|c|}
\hline \multicolumn{7}{|c|}{ Total de exportaciones Brasil 2008 a 2012} \\
\hline Año & 2008 & 2009 & 2010 & 2011 & 2012 \\
\hline $\begin{array}{c}\text { US\$ Mil millones } \\
\text { (FOB) }\end{array}$ & 197,942 & 152,995 & 210,915 & 256,039 & 242,579 \\
\hline
\end{tabular}

Fuente: SECEX - Secretaria de comércio exterior de Brasil - http://www.mdic.gov.br

Según la Secex ${ }^{9}$ Brasil exporta a varios países. Entre ellos podemos destacar los siguientes como los principales destinos: China (US\$ 41.227 mil millones), Estados Unidos (US\$ 26.700 mil millones), Argentina (US\$ 17.997 mil millones), los Países Bajos (Holanda) (US\$ 15.040 mil millones) y Japón (US\$ 7.955 mil millones). Como hablamos del país objetivo de este estudio, Paraguay aparece en la lista de los 23 mayores compradores de productos brasileños con US\$2.617 mil millones dólares.

El Industrial Busse ${ }^{10}$ es una empresa de rápido crecimiento. Con la expansión de los mercados, junto con la buena fase de la agricultura nacional, la compañía está

\footnotetext{
${ }^{9}$ SECEX - Secretaria de comércio exterior de Brasil

${ }^{10}$ Industrial Busse máquinas e implementos agrícolas Itda
} 
aumentando cada año su volumen de negocios, que está girando alrededor de US\$ 5 millones.

Dentro del plan de expansión de la empresa, la expansión del mercado internacional es una meta. Hoy en día, la participación de las exportaciones en volumen de negocio de la compañía sigue siendo modesta y gira en torno al $3 \%$.

Tabla 4: Facturación IBL $x$ exportación

\begin{tabular}{|c|c|c|c|c|c|}
\hline \multicolumn{7}{|c|}{ Ingresos de IBL X exportación } \\
\hline & $\mathbf{2 0 0 8}$ & $\mathbf{2 0 0 9}$ & $\mathbf{2 0 1 0}$ & $\mathbf{2 0 1 1}$ & $\mathbf{2 0 1 2}$ \\
\hline Facturación & 4.241 .051 & 4.033 .134 & 5.482 .432 & 5.798 .577 & 4.395 .308 \\
\hline Exportaciones & 138.254 & 67.528 & 105.239 & 118.323 & 145.177 \\
\hline $\begin{array}{c}\text { Comparativo } \\
\text { Exp x Ing. total }\end{array}$ & $3,25 \%$ & $1,67 \%$ & $2 \%$ & $2 \%$ & $3,3 \%$ \\
\hline
\end{tabular}

Fuente: IBL - 2013

Grafico 2: Facturación IBL x exportación

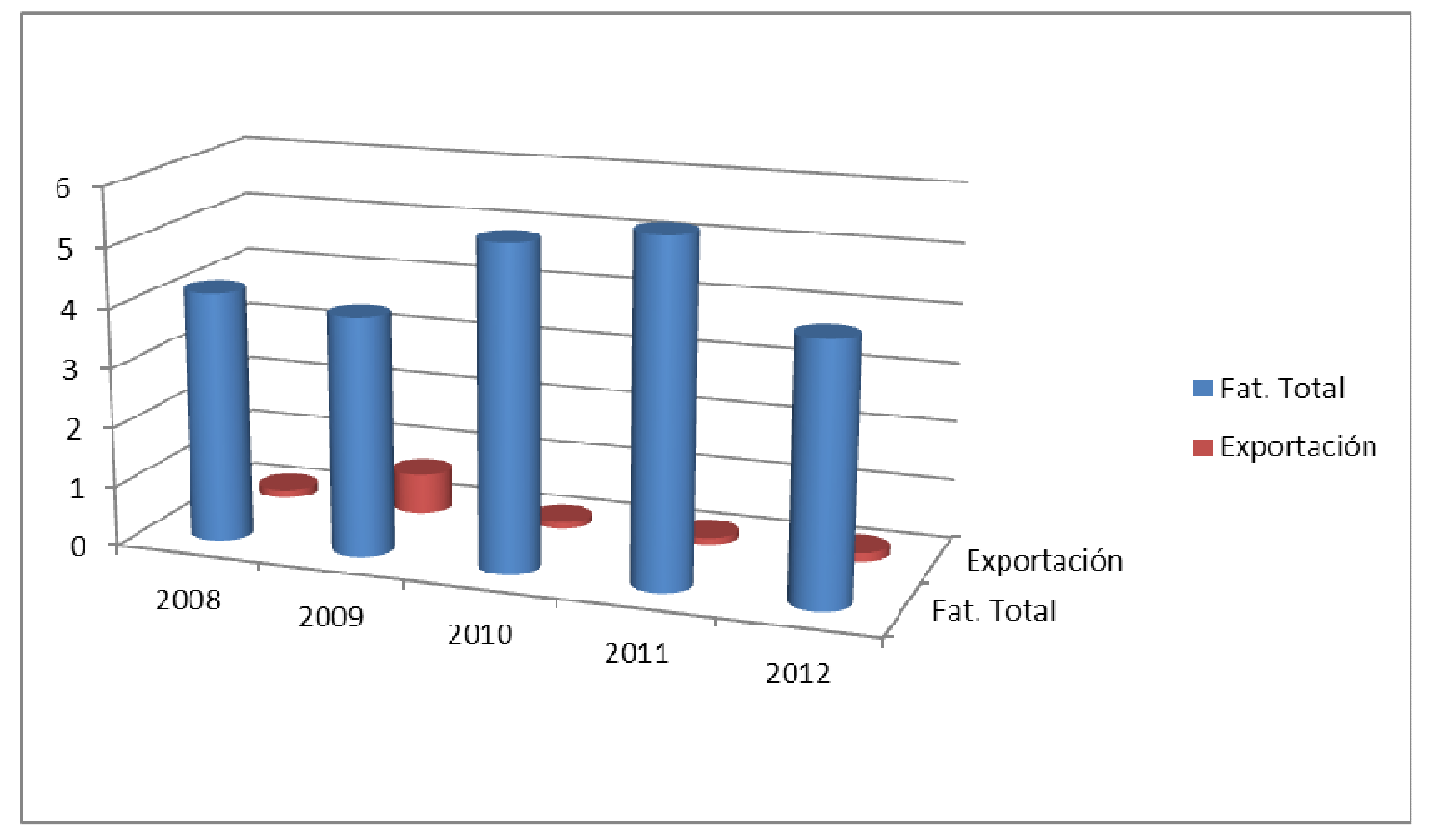

Las negociaciones con el mercado objetivo de este trabajo tienen una larga historia que abarca más de 20 años de actividad. Al principio eran productos como molinos de cereales, acoplados agrícolas de madera y rastras niveladoras. Con los 
años los productos fueron mejorados, nuevos fueron lanzados y recibieron espacio en las negociaciones.

La compañía conoce todos los beneficios que las exportaciones pueden traer, pero teme mucho las variaciones de cambio, ya que cuando el real se deprecia, el producto final se vuelve más caro para el importador, a menudo perdiendo su atractivo.

De acuerdo con la empresa IBL ${ }^{11}$, el único destino de las exportaciones de IBL se reduce a Paraguay. Hace años era común exportar a Argentina y Uruguay, pero con el paso de los años estos países dejaron de comprar y al mismo tiempo el mercado interno brasileño ha decaído cada vez más. En 2009 se produce una exportación para Angola. En esa oportunidad la empresa exportó acoplados agrícolas con cuerpo de madera.

Una iniciativa que tiene la empresa es siempre participar en ferias y reuniones internacionales de negocios. Con eso se consiguen muchos contactos alrededor del mundo, muchos importadores investigan los precios y buscan informaciones y generan futuras oportunidades de negocio.

\subsection{Metas para ampliación del mercado externo}

Siempre con un pensamiento dirigido a la modernización y optimización de los procesos internos, IBL prepara un crecimiento gradual de las exportaciones. Además del mercado objetivo de este estudio, la intención es explorar nuevos mercados y crear nuevos socios en el extranjero, debido a que la exportación eventual no es buena para la empresa, ya que no genera ventas continuas. Se habla de un crecimiento gradual a medida que el mercado interno aumenta y no se puede quedar sin suministros. La empresa cuenta con un número de clientes y revendedores, que sería un riesgo abandonar para volcarse al mercado externo en detrimento del abastecimiento del mercado interno. La compañía cree que con la renovación del parque industrial, la inversión en la producción, investigación y desarrollo de ingeniería y la inversión en personal, será capaz de abastecer satisfactoriamente el mercado nacional y ampliar su mercado exterior, significando las exportaciones al menos al $5 \%$ de las ventas totales.

\footnotetext{
${ }^{11}$ Industrial Busse máquinas e implementos agrícolas Itda
} 
Con relación específica al mercado paraguayo, IBL proyecta un crecimiento muy grande, teniendo en cuenta que en este país existe gran potencial de producción. Agricultura y ganadería son los principales responsables del desarrollo y la generación de riqueza de esa nación. Hay muchas tierras fértiles y los cultivadores están exigiendo cada vez más en términos de mecanización agrícola, porque se focalizan en la productividad.

\section{7 - ANÁLISIS DEL AMBIENTE EXTERNO (Información ofrecida por la empresa IBL)}

IBL ya está en el mercado paraguayo desde hace 20 años, siempre con el mismo socio comercial, la empresa Tracto Agrovial S.A. Esta relación se mantiene desde hace mucho tiempo porque las dos empresas siempre han trabajado seriamente en estos años, compartiendo buenos momentos y también los de dificultad. La Tracto tiene su oficina principal en la ciudad de Asunción y cuenta con 8 sucursales distribuidas en las principales regiones agrícolas del país. Durante todo el tiempo que las empresas forman esa asociación, muchos productos ya fueron vendidos, pero la venta de tolvas se inició hace poco, sólo en el año 2011 con la apertura de la sucursal de Santa Rita, región principalmente agrícola y comprador de maquinaria. La IBL no atiende consumidores finales, este servicio es ofrecido por la Tracto, dado que tiene una estructura de servicio grande, con vehículos y personal especializado. Con las constantes visitas realizadas a las propiedades se pudo recopilar información acerca de lo que son las necesidades de los productores. Estas necesidades se compilan y se transmiten al fabricante, que a su vez busca satisfacer y desarrollar productos que realmente se adapten a los deseos de los agricultores.

\subsection{Análisis de escenarios}

A partir de este momento serán analizados los aspectos demográficos, económicos, político-legales, socio-culturales y naturales, tecnológicos y también competitivos. 


\subsection{Ambiente demográfico}

De acuerdo con el sítio de la Presidência de la República del Paraguay ${ }^{12}$, hoy este país tiene cerca de 7,4 millones de habitantes, no existen datos oficiales sobre la composición étnica de Paraguay. Los organismos nacionales vinculados con el sentido, no incluyen los artículos de la raza o la composición étnica de la población, a pesar de que incluye el porcentaje de indígenas en el país que llega al 1,7\% de la población. Hay un gran índice de ascendencia europea, en su mayoría español, alemán e italiano. En los últimos años han crecido cada vez más concentraciones de agricultores brasileños que viven en este país.

Según Wikipedia, aunque no existen datos oficiales sobre la composición étnica de Paraguay, se estima que la mayoría de la población es el resultado del mestizaje entre los pueblos indígenas y los inmigrantes europeos que comenzaron en la era de la dominación española. La población actual está compuesta por descendientes de un nuevo mestizaje entre la población tradicional hispano-guaraní que sobrevivió al exterminio durante la Guerra del Paraguay y los inmigrantes (especialmente los europeos y los asiáticos) que llegaron después de la Guerra del Paraguay con el fin de repoblar el país. A finales del siglo XX, el número de habitantes aumentó a un ritmo de 2,6\% por año. Con el rápido ritmo de crecimiento, la población se duplicará en un período de 21 años.

La página web oficial del Estado del Paraguay informa que la densidad de población es considerada baja (14,1 hab. / Km²). Hay grandes contrastes de ocupación entre las diferentes partes del país: el Chaco es la región más despoblada. Las llanuras cerca del río Paraná tienen densidad moderada.

La misma fuente dice que el porcentaje de la población urbana es de 56,7\%. Los habitantes se concentran en las grandes ciudades como Asunción, Ciudad del Este, San Lorenzo y Fernando de la Mora. La tasa de natalidad es alta - cada mujer tiene en promedio 3,8 hijos. La tasa de mortalidad infantil es moderada y es de alrededor de 26 por mil. La esperanza de vida es de 68,5 años para los hombres y 73 años para las mujeres.

Según la Wikipedia, el catolicismo es la religión más popular, no oficial desde la constitución actual. La Constitución de 1992 permite el libre ejercicio de cualquier

\footnotetext{
${ }^{12}$ http://www.presidencia.gov.py/v1/
} 
religión o creencia. $89,6 \%$ de la población es católica y el 6,2\% protestante, predominantemente Menonita. También hay minorías, incluyendo $1.1 \%$ de los cristianos de otras afiliaciones, otras religiones $1,9 \%$ y el $1,1 \%$ de los ateos.

\subsection{Ambiente económico}

De acuerdo con la agencia CIA en la sesión The world factbook ${ }^{13}$ y el ministerio de la agricultura del Paraguay ${ }^{14}$, la economía paraguaya se basa en la agricultura y los productos forestales, que representan el $75 \%$ de las exportaciones. Entre los recursos agrícolas se destacan la caña de azúcar, algodón, soja y tabaco. El país también produce cereales, maíz, yuca y yerba mate, un alimento básico tradicional de los habitantes. La industria ganadera está muy desarrollada. En orden de importancia, cuenta con ganado vacuno, porcino y ovino. Las principales especies de maderas comerciales de exportación son quebracho, caoba, nogal y cedro.

Paraguay tiene industrias de yerba mate, de cerveza, alimenticia, el tabaco, el ron y alcohol, la preparación de la carne y los cueros y vinculado a la exportación de aceite de soja, de taninos, de parquet y madera tira. Sus represas, como la Central Hidroeléctrica de Itaipú (cofinanciado con Brasil), proporcionan un índice de energía que cubre $175,2 \%$ - muy por encima del consumo interno, sino que también tiene la planta del Acaray Hernandarias y de Yacyretá, que se está construyendo en colaboración con Argentina. Los cursos de agua de los ríos Paraná y Paraguay sirven como carreteras.

De los países vecinos, Paraguay importa principalmente maquinaria, materiales de construcción, textiles y productos químicos.

Paraguay exporta electricidad - los ingresos cubren las importaciones de petróleo. El país es autosuficiente en trigo y otras materias primas alimentarias. Tiene una gran dependencia de la agricultura (la actividad representa el 50\% del PIB y el $90 \%$ de las exportaciones). Cuenta con pocos minerales explotados comercialmente. En 2010, Paraguay logró la mayor expansión económica en la región y la más alta de América Latina, con un crecimiento del PIB de $13 \%$.

En cuanto a la agricultura, las pequeñas granjas producen maíz, yuca, caña de azúcar y tabaco, con el uso de técnicas primitivas en general. Pero con la apertura de la colonización oriental del país para los inmigrantes brasileños en los años setenta, ochenta y principios de los noventa, las tierras de cultivo cambiaron

\footnotetext{
${ }^{13}$ https://www.cia.gov/library/publications/the-world-factbook/geos/pa.html

${ }^{14}$ http://www.mag.gov.py/
} 
mucho. Hoy en día, los grandes conglomerados hicieron aumentar la cotización de las tierras. La agricultura está muy desarrollada, sobre todo en el cultivo de la soja y el maíz cómo segundo cultivo. El advenimiento de la tecnología y los técnicos formados en el país, incluso aquellos que vinieron de países vecinos han contribuido a la explotación de los casi 3 millones de hectáreas explotadas en la agricultura empresarial. Las regiones de cultivo de algodón se encuentran a lo largo del río Paraguay en el Chaco, y el cultivo de tabaco en el sur. La yerba mate se cultiva, principalmente para consumo, en la parte oriental del territorio. Se cultiva la naranja amarga, que es de importancia, ya que por destilación de su cáscara se consigue una esencia clave para la industria de la perfumería.

Según la periodista Nancy Pérez ${ }^{15}$ en el rebaño paraguayo prevalece el ganado vacuno, con aproximadamente 8.074 .000 cabezas, además de porcino, equino y lanar. El ganado vacuno mejor adaptado a las condiciones del país es el de la raza Criolla, excelente para la fabricación de charque, conservas y productos y subproductos. La producción de carne en todas sus fases, es en el ámbito de un organismo gubernamental, la Corporación Paraguaya de Carnes (COPACAR). La ganadería se cría extensivamente y las principales zonas de reproducción son los campos del Chaco y en el departamento de Itapúa.

Los principales ríos tienen gran potencial para la pesca, pero la misma se practica de manera artesanal.

Acerca de las importaciones, Paraguay tuvo en los últimos años un volumen de US\$ 8,13 mil millones en promedio anual, como se puede ver en la tabla de la balanza comercial del país.

Tabla 5: Balanza comercial paraguaya 2008 - 2012

\begin{tabular}{|c|c|c|c|c|c|}
\hline \multicolumn{7}{|c|}{ Tabla balanza comercial paraguaya 2008 - 2012 } \\
\hline & $\mathbf{2 0 0 8}$ & $\mathbf{2 0 0 9}$ & $\mathbf{2 0 1 0}$ & $\mathbf{2 0 1 1}$ & $\mathbf{2 0 1 2}$ \\
\hline & 6,47 & 5,09 & 7,74 & 9,45 & 11,90 \\
\hline Importaciones & 4,33 & 3,08 & 4,36 & 5,33 & 8,80 \\
\hline Exportaciones & $-2,14$ & $-2,01$ & $-3,38$ & $-4,12$ & $-3,10$ \\
\hline Saldo & & & & & \\
\hline
\end{tabular}
${ }^{15}$ http://www.abc.com.py/articulos/la-ganaderia-ha-acompanado-al-paraguay-durante-toda-su-
historia-246553.html 
Fuente: Bladex - Banco latinoamericano de comercio exterior, S.A.http://www.bladex.com/

El hecho de que Paraguay no ha fortalecido el sector industrial, se refleja en la importación de diversos artículos. Otra cuestión que aumenta el nivel de las importaciones de este país es la fuerte actividad de las empresas maquiladoras que importan materiales sin pagar impuestos, siendo su producto específico y que no será vendido en el país.

El comercio entre Brasil y Paraguay está creciendo cada año. Brasil es el segundo mayor exportador de mercancías a Paraguay, segundo lugar después de China.

Cuadro3: Principales países importadores y exportadores

\begin{tabular}{cc|cc}
\hline \multicolumn{2}{c}{ Exportaciones } & Por países \\
\hline Por países & & China & $38.1 \%$ \\
Uruguay & $20.9 \%$ & Brasil & $26.7 \%$ \\
Brasil & $13.9 \%$ & Argentina & $17.1 \%$ \\
Chile & $11.5 \%$ & .
\end{tabular}

Fuente: Bladex - Banco latinoamericano de comercio exterior, S.A.- http://www.bladex.com/

Por su parte, la balanza comercial del intercambio entre Brasil y Paraguay tuvo los siguientes índices:

Cuadro4: Balanza comercial entre Brasil y Paraguay

\begin{tabular}{cc|cc}
\hline \multicolumn{2}{c}{ Exportaciones } & \multicolumn{2}{c}{ Importaciones } \\
\hline \multicolumn{2}{c}{ En mil millones de US\$ } & \multicolumn{2}{c}{ En mil millones de US\$ } \\
2008 & 2,48 & 2008 & 0,657 \\
2009 & 1,68 & 2009 & 0,585 \\
2010 & 2,54 & 2010 & 0,611 \\
2011 & 2,96 & 2011 & 0,715 \\
2012 & 2,61 & 2012 & 0,987 \\
\hline
\end{tabular}

Fuente: MDIC - Ministério do desenvolvimento indústria e comercio exterior - Governo brasileiro 
Grafico 3: Comparación de la balanza comercial Brasil X Paraguay

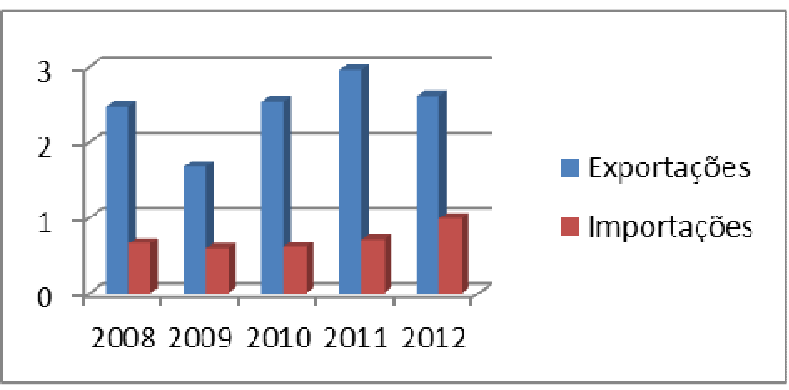

Fuente: MDIC - Ministério do desenvolvimento indústria e comercio exterior - Governo brasileiro http://www.mdic.gov.br

\subsection{Ambiente político}

Según la enciclopedia Abril ${ }^{16}$, el Paraguay es una república presidencial, donde el presidente es, al mismo tiempo, el jefe de Estado y de Gobierno. La Constitución de Paraguay, promulgada en el 20 de agosto de 1992, establece que el país es una república basada en la democracia y la separación de poderes.

En la misma enciclopedia se ofrece datos que dicen que, a finales de 1980, el deterioro de la salud del general Alfredo Stroessner y la consiguiente incapacidad para hacer frente a los golpes de Estado, conflictos militares, la sucesión y el descontento económico llevaron al general Andrés Rodríguez al poder en 1989 mediante un golpe de Estado. Su promesa de la democracia se cumplió en 1993 con las primeras elecciones libres después de sesenta años de gobierno militar. El Partido Colorado, el antiguo partido gobernante de Stroessner, todavía tenía el apoyo suficiente para ganar las elecciones para el Congreso y la Presidencia. Pero Guillermo Caballero Vargas en representación del PEN (Partido Encuentro Nacional), uno de los exponentes de la ideología de nuevo mercado (concepto del Partido de Caballero Vargas), tuvo la mitad de los votos en Asunción.

En cuanto al poder ejecutivo, es ejercido por el presidente, elegido por sufragio universal directo por un período de cinco años sin posibilidad de reelección. El presidente, que es asistido por el vicepresidente, debe nombrar los ministros.

\footnotetext{
${ }^{16}$ Enciclopédia Abril (em português). 33ạ ed. São Paulo: Abril, 2007. 568-569 p. 1 vol. vol. 1.
} 
El presidente y el vicepresidente son asesorados por el Consejo de Ministros. El Presidente participa en la formulación de la legislación y promulga, y puede vetar las leyes hechas por el legislador.

El Consejo de Ministros está formado por los miembros del gabinete, el rector de la Universidad Nacional de Asunción, el presidente del Banco Central del Paraguay y representantes de los siguientes ministerios de: agricultura y ganadería; educación y cultura; finanzas; relaciones exteriores; industria y comercio; interior; justicia; defensa; salud y bienestar; obras públicas y comunicaciones. El poder legislativo es bicameral, compuesto por el Senado (45 miembros) y la Cámara de Representantes (80 miembros); senadores y diputados tienen cinco años en el cargo. Las elecciones al Congreso se celebran en listas cerradas de forma simultánea con la elección presidencial (no es pertinente para votar por cada candidato a diputado o senador, sino por una lista presentada por cada partido político). Los diputados son elegidos por el departamento, mientras que los senadores son elegidos a nivel nacional, todos por períodos de cinco años.

\subsection{Ambiente geográfico y natural}

La enciclopedia Barsa ${ }^{17}$ transmite que Paraguay limita con Bolivia, al norte y al noroeste, con Brasil al este y noreste, y Argentina hacia el sureste, sur y oeste. La ubicación de Asunción se encuentra en la margen izquierda del río Paraguay, frente a la desembocadura del río Pilcomayo. El río Paraguay desciende desde la parte norte hacia la zona sur dividiendo Paraguay en dos regiones geográficas distintas- Región Oriental y Región Occidental. Otro nombre que se dá a éste último, es el Chaco Boreal.

En Paraguay hay tres regiones geográficas diferentes: el Gran Chaco, el campo y el bosque.

El Chaco es una gran extensión de llanura en la parte occidental del país. Compartiendo con Bolivia y Argentina, se caracteriza por la altitud que declina gradualmente desde la parte noroccidental hacia la parte sur-oriental. Zona pantanosa que se inunda durante la temporada de lluvias.

\footnotetext{
${ }^{17}$ Enciclopédia Barsa (em português). Enciclopédia Britânica do Brasil Publicações.
} 
El campo ocupa la región central. El relieve es de colinas y de valles serranos fértiles. Los tipos de vegetación característica son la sabana, bosque de galería y la vegetación de pantano.

La superficie forestal se encuentra en una forma de relieve de las tierras bajas. Las colinas bajas cortan a través de esta región y alcanzan a unos 700 metros de las cordilleras de Amambay y Mbaracayú, ambas en la frontera con Brasil.

La red hidrográfica es muy importante para el país. Se compone de los ríos Paraná y Paraguay que sirven de límite natural con Brasil; por Pilcomayo, que es originario de Bolivia y es un afluente de la margen oeste del Paraguay; y las formas de relieve lacustres de Ypoá, del Ypacaraí y del Verá.

El clima tiene variación tropical a subtropical. Sus temperaturas son altas y las precipitaciones son abundantes en la mayor parte del año.

Figura1: Mapa demonstrando límites de fronteira do Paraguai

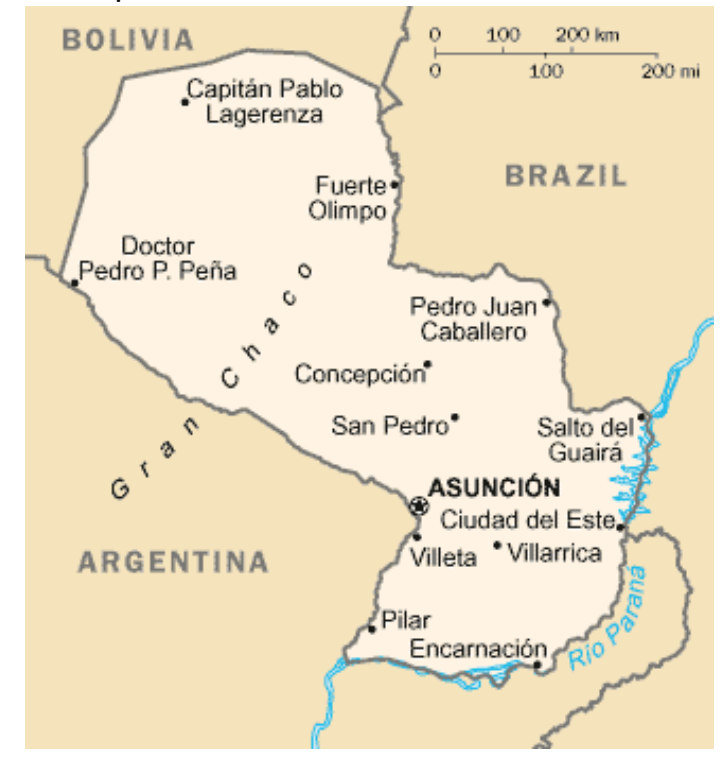

Fuente: Wikipedia

\subsection{Situación actual del productor agrícola paraguayo}

Paraguay desde el comienzo de su historia fue demasiado explotado e incluso devastado por la guerra, la población masculina fue casi diezmada. Con esto, el país ha sufrido y sigue sufriendo con problemas sociales, de salud, educación y otros. 
Teniendo un suelo muy fértil, abundante naturaleza y clima que contribuye a la producción agrícola y ganadera, Paraguay en los últimos años ha alcanzado un gran crecimiento a través de la agroindustria.

Con muy pocas industrias de maquinaria agrícola, Paraguay importa la mayor parte de las máquinas agrícolas utilizadas en la producción. El principal proveedor es Brasil.

Según el ministerio de la agricultura del Paraguay, el gobierno paraguayo tiene algunos programas de apoyo a la agricultura, pero dirigidos principalmente a la agricultura familiar. Un ejemplo es el PRONAF (Programa nacional de apoyo a la agricultura familiar, del ministerio de la agricultura y ganadería de Paraguay www.mag.gov.py), este programa tiene como objetivo:

- Promover la diversificación de actividades productividades acorde a la conveniencia de las familias dedicadas a la agricultura familiar.

- Asegurar la producción de rubros de consumo de las familias incorporadas al programa.

- Incrementar el nivel de implementación de tecnologías agropecuarias y forestales sostenibles.

- Proveer apoyo financiero a las unidades productivas familiares mediante criterios técnicos establecidos.

- Desarrollar un sistema de apoyo directo a las fincas familiares afectadas por contingencias climáticas.

- Alianzas operativas con organismos locales (gobernaciones, municipalidades, cooperativas, ONGs, empresas privadas) de atención a la agricultura familiar.

También existe la Dirección de Extensión Agraria (oficina integrada al ministerio de la agricultura paraguayo www.mag.gov.py), tiene a su cargo la asistencia técnica integral al productor, mediante el desarrollo de acciones conducentes, para que el productor adopte los materiales biológicos y los métodos más ventajosos, concernientes a la producción, manejo y comercialización de sus productos; así como la aplicación de técnicas de conservación de sus recursos productivos y del medio ambiente.

Por mucho que Paraguay importe la mayor parte de la maquinaria e insumos agrícolas, los agricultores tienen muchas opciones para la elección de ellos. 
Una mayor gravación impositiva no incide en la demanda de maquinarias agrícolas provenientes de Brasil.

Por otro lado, hay agricultores que no tienen acceso a líneas de crédito y, son aquellos, que viven en situación precaria y por lo tanto no pueden producir. Hay varias zonas de difícil acceso, sin carreteras, sin infraestructura adecuada para la práctica de la agricultura y / o ganadería.

Hay varios factores que influyen en el cliente en el momento de la compra, pero la principal es, sin duda, la situación actual de la producción y la cotización de los productos agrícolas. Siendo bienes de capital y duraderos en el tiempo maquinaria e implementos agrícolas, requieren un análisis más detallado por parte de los clientes, al momento de invertir su capital, que en este caso es considerablemente alto.

Según informaciones de Tracto Agrovial (empresa importadora de máquinas www.tractoagrovial.com.py) es común en Paraguay la entrada de cosechadoras cada vez más rápidas y de alto rendimiento, que ayudan a trabajar más rápido y resulta una mayor productividad. Así, la demanda de tolvas de igual rendimiento es constante. Los productores paraguayos están buscando tolvas más grandes, que permitan una descarga acelerada, ofreciendo calidad a un precio justo. Además de estas características, estas máquinas deben estar equipadas con caja de herramientas, señal trasera, accionamiento hidráulico de la compuerta y tuberías de descarga, así como otras opciones como: cubierta de lona, balanza y enganche trasero.

Las tolvas IBL no cumplen con todos estos requisitos, se mantiene una excelente calidad, como se reconoce en el mercado paraguayo, pero las máquinas no tienen la capacidad ni tasa de descarga requerida y no viene con las opciones que buscan los clientes. La mayor ventaja que ofrece IBL es un producto de alta calidad a un precio justo.

A principios de 2013, IBL lanzó en Brasil el ABA 12500, una tolva multiuso. Esta máquina trata de proporcionar a los agricultores el aumento de los períodos de uso de los equipos, pues puede ser utilizada tanto como el transbordo de grano como para suministrar el plantador durante la siembra. De acuerdo a las entrevistas con algunos clientes en las ferias en Paraguay se encontró que esta máquina, que todavía no se vende allí, tendrá una excelente aceptación. Muchos clientes compran tolvas y 
utilizan sólo en la cosecha, lo que hace con que su capital invertido se quede parado sin poder ser utilizado en otras épocas del año.

Un factor clave para la venta de máquinas es el hecho de que a los clientes les gusta ver las máquinas en funcionamiento. IBL no realiza demostraciones de productos en el Paraguay, el trabajo de divulgación se hace por los vendedores de la representante local y también por los clientes que compran las máquinas y las divulgan a sus conocidos.

\subsection{Producción de granos}

Los paraguayos, así como los brasileños, son muy influenciados por buenas perspectivas para las cosechas y los precios consistentes. Esto también define compras, pues si el productor está animado y tiene facilidades de compra, la venta se realiza en medio de esta animación.

En la región cubierta por el Busse industrial, es decir, la región que abarca las provincias de Itapúa, Alto Paraná y Guairá, hay muchos agricultores provenientes de Brasil, o incluso que residen en Brasil y producen en Paraguay. Estas personas son muy conocedoras de la maquinaria agrícola de Brasil y así que cuando compran prefieren productos de esta nacionalidad. También en esta región se ha producido un gran desarrollo de las técnicas agrícolas. Es realmente notable cada año, el avance que se produce en términos de la producción de granos. La región en sí misma tiene un suelo rico y adecuado para la agricultura, por lo tanto varias inversiones en la investigación de nuevas especies, combinado con una buena fertilización, mejora del suelo y, agregando, máquinas más modernas y ágiles que evitan el desperdicio, obtienen los éxitos sucesivos en la producción agrícola. Con la excepción de 2011, cuando hubo una gran sequía, los últimos 5 años fueron de aumento de la producción. 
Grafico 4: Evolución de la producción de soja en el Paraguay

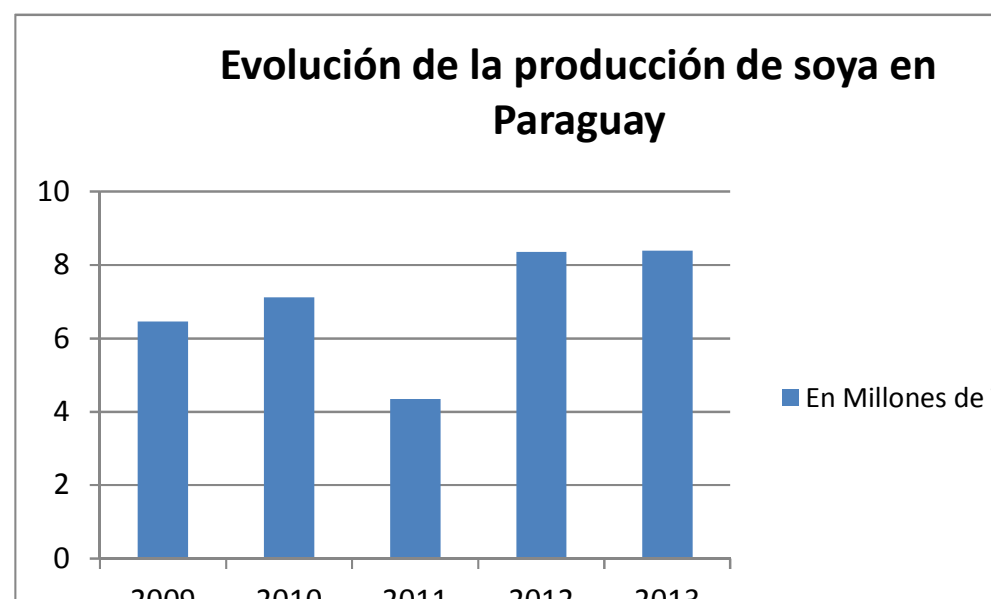

Fuente: Ministerio de la agricultura del gobierno paraguayo (www.mag.gov.py)

Se puede ver entonces que la producción de maíz en Paraguay en las últimas cinco temporadas ha promediado 2,8 millones de toneladas, dejando de esta manera después de la producción de soja un promedio de 7,0 millones de toneladas.

Grafico 5: Evolución de la producción de maíz en el Paraguay

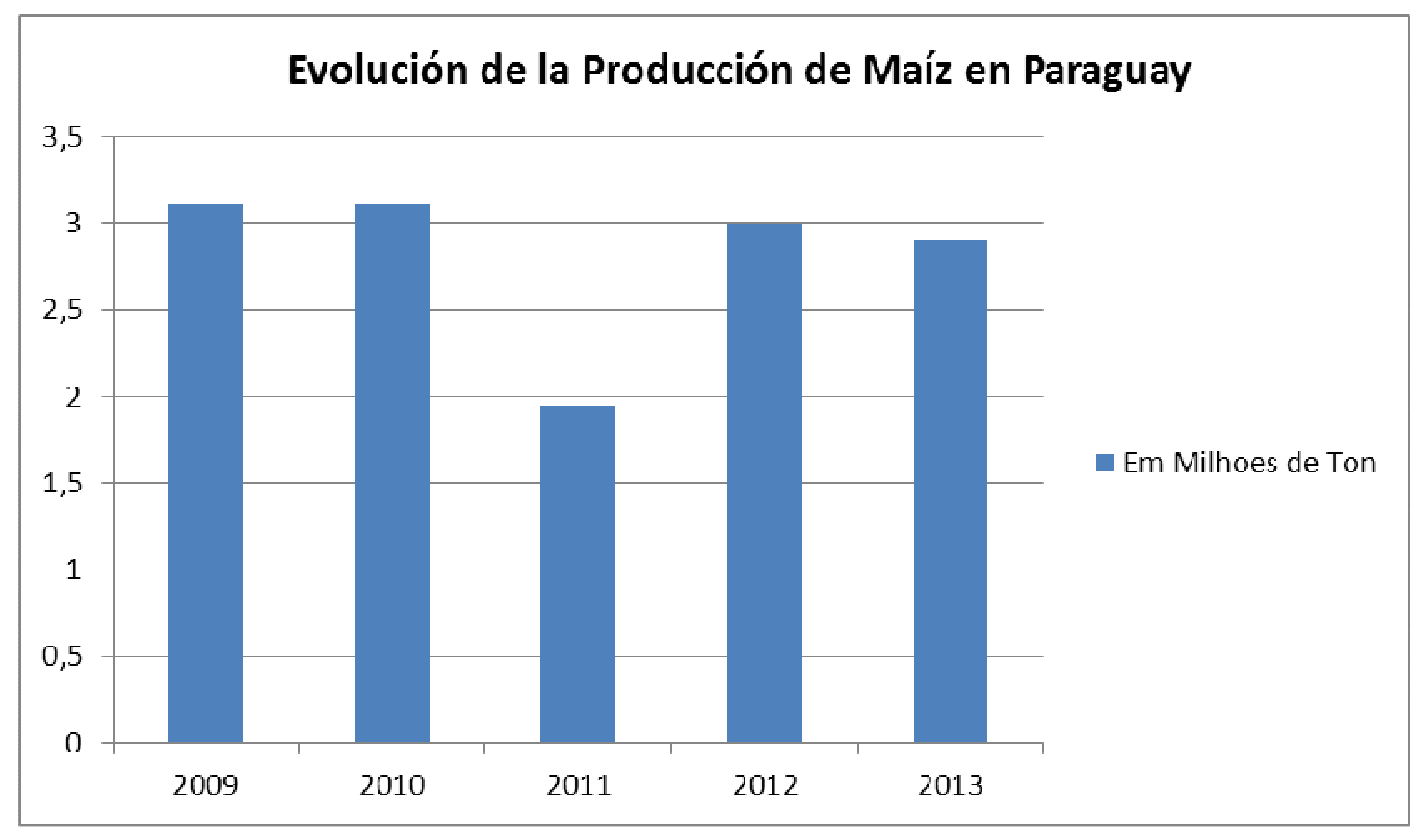

Fuente: Ministerio de la agricultura del gobierno paraguayo (www.mag.gov.py) 


\subsection{Análisis de la competencia}

Cuando se trata de la competencia en la industria de maquinaria agrícola, se está hablando de un sector con competencia pura. La evolución se produce todos los días, se crean muchos implementos de máquinas, mejorados e incluso copiados, dado que el producto y el servicio que se ofrecen son los mismos para todos los players (competidores).

De acuerdo con SIMERS ${ }^{18}$, dentro de este segmento hay numerosas posibilidades de compra. Las principales diferencias son las siguientes:

- Volumen

- Capacidad de Descarga

- Número de ejes

- Tipo de rueda

- Sistema de accionamiento

- Accesorios

- Precio

- Funcionalidad

De acuerdo a estos factores se crean diferentes tipos de máquinas dentro del segmento Tolvas. Todo esfuerzo tiene como objetivo satisfacer los diferentes tipos de consumidores.

En el mercado paraguayo, se puede decir que las tolvas IBL sufren una dura competencia principalmente de Argentina y también de Brasil.

\subsubsection{Competencia argentina}

Las máquinas que vienen especialmente de Argentina tienen muy buena aceptación en Paraguay, además de robustas, tienen una alta capacidad de carga y gran número de accesorios. Esta buena aceptación de las máquinas argentinas se debe mucho al hecho de que este país es un gran productor de granos y por lo tanto tiene un gran know-how en la producción de implementos para lograr este propósito. Con las tolvas no es diferente, podemos destacar los siguientes fabricantes:

18 SIMERS - Sindicatos do fabricantes de máquinas e implementos agrícolas do Rio Grande do Sul Brasil 


\subsubsection{Máquinas Ombu}

Según el sitio del fabricante Ombu, la empresa está ubicada en la provincia de Santa Fe, es productora de maquinaria agrícola desde 1990, desde entonces ha crecido y creado nuevos productos. Cuenta con una gran penetración en el mercado paraguayo, donde es muy bien aceptada. La Ombu exporta a varios países, entre ellos Brasil y también tiene una planta de fabricación en la ciudad de Puerto Ordaz en Venezuela.

Tabla 6: Productos Ombú

\begin{tabular}{|c|c|c|}
\hline \multicolumn{3}{|c|}{ Tolvas Ombu } \\
\hline Tipo & Capacidad (Vol) & Característica \\
\hline Tolva & $32.000 \mathrm{~L}$ & 2 Ejes \\
\hline Tolva & $20.000 \mathrm{~L}$ & 2 Ejes \\
\hline Tolva & $10.800 \mathrm{~L}$ & 1 Eje \\
\hline Tolva & $9.500 \mathrm{~L}$ & 1 Eje - cónica \\
\hline Fuente: Máquinas Ombu - www.ombu.com.ar
\end{tabular}

El análisis de los productos Ombu permite observar que la competencia directa con los productos IBL son las Tolvas de $9.500 \mathrm{~L}$ y $10.800 \mathrm{~L}$. Ambos productos tienen las mismas características de los modelos Granera 140 y Super Granera 170. Las ventajas del competidor es tener una mayor resistencia, mayor velocidad de descarga y diversos componentes y accesorios. El sitio web de la empresa tiene muchas informaciones, incluyendo manuales, dibujos y listados de piezas. Se trata de una marca con estructura internacional de distribución y divulgación de sus productos.

\subsubsection{Industrias Montecor}

Según el fabricante, esta es una compañía aún más modesta con cerca de 100 empleados. Se encuentra ubicada en la ciudad de Monte Buey en la provincia de Córdoba. Tiene hoy una planta industrial con $6.000 \mathrm{~m}^{2}$ que produce varios modelos de maquinaria agrícola.

Industrias Montecor ha interiorizado las necesidades de sus clientes, y sus productos cubren las expectativas de los pequeños y grandes productores. La gran variedad de productos y de modelos permiten que todos sus clientes puedan tener una alternativa a la hora de comprar. La gama de productos, acoplados tolvas, tolvas autodescargables, carros distribuidores, roto enfardadoras, acoplados playos, acoplados 
para transporte de hacienda, tanques de combustibles, mixers y mezcladores de forrajes tiene una alternativa para cualquiera necesidad.

Gracias al trabajo constante y al tesón de los que componen Industrias Montecor; sus productos han cruzado las fronteras y se venden a nuestros hermanos de Bolivia, Paraguay, Uruguay y Chile.

Tabla 7: Productos Montecor

\begin{tabular}{|c|c|c|}
\hline \multicolumn{3}{|c|}{ Tolvas Montecor } \\
\hline Tipo & Capacidad (Vol) & Característica \\
\hline Tolva & $10.000 \mathrm{~L}$ & 1 Eje - cónica \\
\hline Tolva & $15.000 \mathrm{~L}$ & 1 Eje \\
\hline Tolva & $20.000 \mathrm{~L}$ & 1 Eje y 2 Eje \\
\hline Tolva & $22.000 \mathrm{~L}$ & 2 Ejes \\
\hline Tolva & $26.500 \mathrm{~L}$ & 2 Ejes \\
\hline Tolva & $32.000 \mathrm{~L}$ & 2 Ejes \\
\hline Tolva & $37.000 \mathrm{~L}$ & 2 Ejes \\
\hline
\end{tabular}

Fuente: Industrias Montecor - www.industriasmontecor.com.ar

Aunque no tenga una gran estructura industrial, la Montecor ha evolucionado considerablemente desde su fundación a mediados de los años 70 . Tiene una gran línea de Tolvas, desarrolladas con alta calidad y componentes de primera calidad. Tiene sitio Web propio con muchas descripciones de productos.

En un comparativo con la IBL, se puede decir que los principales productos competidores son las Tolvas de $10.000 \mathrm{~L}$ y $15.000 \mathrm{~L}$.

\subsubsection{Richiger}

Según el fabricante, la empresa nace en 1959 en Sunchales provincia de Santa Fe, Argentina fundada por don Máximo Richiger. Se inicia como una gran herrería realizando trabajos para la primer fábrica de cosechadoras autopropulsadas del mundo, Rotania, también original de Sunchales. Fabrican en serie cabezales maiceros para esta empresa, comenzando en ese momento el desarrollo de los primeros modelos propios de implementos agrícolas. 
En la actualidad, la empresa cuenta con $8.000 \mathrm{~m} 2$ en zona urbana y $6000 \mathrm{~m} 2$ en el parque industrial de la ciudad de Sunchales. Posee maquinarias de última generación y un equipo de gente altamente capacitado en permanente diálogo con el productor, lo que asegura calidad constante en sus productos. Mediante su red de Concesionarios, se suma un amplio servicio de asesoramiento a clientes y stock permanente de repuestos.

Tabla 8: Productos Richiger

\begin{tabular}{|c|c|c|}
\hline \multicolumn{3}{|c|}{ Tolvas Richiger } \\
\hline Tipo & Capacidad (Vol) & Característica \\
\hline Tolva & $24.000 \mathrm{~L}$ & 1Eje fijo + 1 balancin \\
\hline Tolva & $32.000 \mathrm{~L}$ & 2 Ejes fijos + 1 balancin \\
\hline
\end{tabular}

Fuente: Richiger - http://www.richiger.com.ar/

De acuerdo con Tracto agrovial ${ }^{19}$, las tolvas de marca Richiger están orientadas para grandes propiedades, tienen una gran capacidad y son muy robustas. Estas máquinas no compiten directamente con la línea de tolvas IBL, pero vale destacar que hay una gran demanda de estas máquinas en Paraguay debido al hecho de la necesidad de máquinas con mayor capacidad. Además, las máquinas Richiger tienen diversos accesorios, como la lona para la cubierta, caja de herramientas, balanza, luces y más.

\subsubsection{Akron}

Según el fabricante, la empresa tiene sede en Córdoba, produce y comercializa tolvas auto-descargables, acoplados tolvas para semillas y fertilizantes, embolsadoras y extractoras de granos secos para apoyar eficientemente las tareas de cosecha, post cosecha y siembra.

En 2011 logró el certificado ISO 9001-2008 que vino para garantizar aún más los productos de calidad que la empresa produce.

La Akron es hoy una de las mayores competidoras de IBL en el mercado paraguayo debido al hecho de tener máquinas de diversos tamaños y precios.

\footnotetext{
${ }^{19}$ Tracto agrovial és representante de IBL para el mercado paraguayo
} 
Tabla 9: Productos Akron

\begin{tabular}{|c|c|c|}
\hline \multicolumn{3}{|c|}{ Tolvas Akron } \\
\hline Tipo & Capacidad (Vol) & Característica \\
\hline Tolva & $6.500 \mathrm{~L}$ & 1 Eje - cónica \\
\hline Tolva & $8.500 \mathrm{~L}$ & 1 Eje - cónica \\
\hline Tolva & $14.000 \mathrm{~L}$ & 1 Eje \\
\hline Tolva & $20.000 \mathrm{~L}$ & 2 Ejes \\
\hline Tolva & $22.000 \mathrm{~L}$ & 2 Ejes \\
\hline Tolva & $24.000 \mathrm{~L}$ & 2 Ejes \\
\hline Tolva & $28.000 \mathrm{~L}$ & 2 Ejes \\
\hline
\end{tabular}

Fuente: Akron - www.akron.com.ar

Aun según tracto agrovial, acerca de la competencia con los productos IBL, se puede observar que las principales máquinas son las de $6.500 \mathrm{~L}, 8.500 \mathrm{~L}$ y la de 14.000L. Las demás ya va más allá de la categoría en la que IBL tiene máquinas. Además de tener una gran línea de productos, la Akron cuenta con una amplia red de servicio y post-venta. La empresa exporta a los principales países productores de granos, tales como Australia, Canadá, Estados Unidos, Ucrania, Kazajstán, Sudáfrica, Paraguay y Brasil también, donde desarrolló una asociación con un productor brasileño de máquinas.

\subsection{Competidores paraguayos}

\subsubsection{Oro Verde}

De acuerdo con el fabricante, la empresa está ubicada en la ciudad de Santa Rita, en una región que es gran productora de granos. Tiene la fabricación de tolvas entre otros productos. Se trata de una pequeña empresa y dependen en gran medida de insumos importados, principalmente de Brasil. Su atención se centra en los pequeños y medianos productores, es decir, el mismo enfoque de IBL. Los productos no tienen mucha tecnología y accesorios.

Tabla 10: Productos Oro Verde

\begin{tabular}{|c|c|c|}
\hline \multicolumn{3}{|c|}{ Tolvas Oro Verde } \\
\hline Tipo & Capacidad (Vol) & Característica \\
\hline Tolva & $14.000 \mathrm{~L}$ & 1 Eje \\
\hline Tolva & $32.000 \mathrm{~L}$ & 2 Ejes \\
\hline
\end{tabular}

Fuente: Oro Verde - www.oroverde.com.py 


\subsubsection{Dalazen}

De acuerdo con el fabricante, su ubicación es en la ciudad de Santa Rita, es de propietarios brasileños que han invertido el capital precisamente en esta región productora de granos. Produce un solo tipo de tolva. En su línea de productos cuenta con otros modelos de acoplados agrícolas, plataformas cosechadoras, además de su último lanzamiento, que es un pulverizador autopropulsado.

Tabla 11: Productos Oro Verde

\begin{tabular}{|c|c|c|}
\hline \multicolumn{3}{|c|}{ Tolvas Dalazen } \\
\hline Tipo & Capacidad (Vol) & Característica \\
\hline Tolva & $9.500 \mathrm{~L}$ & 1Eje - Cónica \\
\hline
\end{tabular}

\subsection{Competidores brasileños}

\subsubsection{Jan}

De acuerdo con informaciones de la empresa, la misma está ubicada en la ciudad de Não-me-Toque, estado de Rio Grande do Sul, tiene una estructura sólida construida sobre años de dedicación a los agricultores, lo que resultó en una empresa moderna con amplias instalaciones y un gran potencial tecnológico. Nombrada G. JAN RAUWERS E FILHO, fue fundada el 29 de agosto de 1960 por Gerrit Jan Hermanus Rauwers - inmigrante holandés - y trabajaba en el área de reparaciones mecánicas en general y producción de arados en condiciones artesanales.

Con el tiempo fue evolucionando y transformando el mercado agrícola en la región a la que pertenece, que ahora se conoce como la capital nacional de la agricultura de precisión. 
Tabla 12: Productos Jan

\begin{tabular}{|c|c|c|}
\hline & \multicolumn{2}{|c|}{ Tolvas Jan } \\
\hline Tipo & Capacidad (Vol) & Característica \\
\hline Tolva & $6.000 \mathrm{~L}$ & 1 Eje - cónica \\
\hline Tolva & $10.000 \mathrm{~L}$ & 1 Eje - Transfer \\
\hline Tolva & $10.500 \mathrm{~L}$ & 1 Eje - cônica - Transfer \\
\hline Tolva & $12.000 \mathrm{~L}$ & 1 Eje - cônica - Transfer \\
\hline Tolva & $15.000 \mathrm{~L}$ & 1 Eje - cônica - Transfer \\
\hline Tolva & $10.500 \mathrm{~L}$ & 1 Eje - cônica - polietileno \\
\hline Tolva & $12.000 \mathrm{~L}$ & 1 Eje - cônica - polietileno \\
\hline Tolva & $15.000 \mathrm{~L}$ & 2 Eje - cônica - Transfer \\
\hline Tolva & $20.000 \mathrm{~L}$ & 2 Eje - cônica - Transfer \\
\hline Tolva & $17.000 \mathrm{~L}$ & 2 Eje - cônica - polietileno \\
\hline Tolva & $20.000 \mathrm{~L}$ & 2 Eje - cônica - polietileno \\
\hline Tolva & $17.000 \mathrm{~L}$ & 2 Eje - cônica - inox \\
\hline Tolva & $20.000 \mathrm{~L}$ & 2 Eje - cônica - inox \\
\hline
\end{tabular}

Fonte: Jan - www.jan.com.br

Los Implementos Jan son uno de los líderes en el segmento Tolvas, produce una línea de amplia diversificación de máquinas. Durante los años ha logrado incluir diferentes materiales y componentes a sus productos. Un gran ejemplo es la inserción de polietileno y de acero inox, que permite un mejor uso y conservación cuando se utiliza con fertilizantes. En el caso de competencia con IBL, se pueden citar todas las Tolvas de $6.000 \mathrm{~L}$ a $15.000 \mathrm{~L}$ producidas con acero al carbono, ya que la IBL no produce en polietileno o acero inox.

\subsubsection{Stara}

Según informaciones del SIMERS y APEX (Agencia brasileña de promoción a exportaciones), es el mayor fabricante de maquinaria agrícola e implementos en América Latina. Se inició en 1953 en la ciudad de Não-me-toque, estado de Rio Grande do Sul. Su característica principal es la búsqueda de la tecnología, con los años ha logrado un crecimiento impresionante y hoy sus productos son enviados a países de todo el mundo. 
Tabla 13: Productos Stara

\begin{tabular}{|c|c|c|}
\hline \multicolumn{3}{|c|}{ Tolvas Stara } \\
\hline Tipo & Capacidad (Vol) & Característica \\
\hline Tolva & $16.000 \mathrm{~L}$ & 1 Eje \\
\hline Tolva & $25.000 \mathrm{~L}$ & 2 Eje - Transfer \\
\hline Tolva & $32.000 \mathrm{~L}$ & 2 Eje - Transfer \\
\hline Tolva & $25.000 \mathrm{~L}$ & 2 Eje - inox \\
\hline Tolva & $11.000 \mathrm{~L}$ & 1 Eje - polietileno \\
\hline Tolva & $12.000 \mathrm{~L}$ & 1 Eje - polietileno \\
\hline Tolva & $14.000 \mathrm{~L}$ & 2 Eje - polietileno \\
\hline Tolva & $16.000 \mathrm{~L}$ & 2 Eje - polietileno \\
\hline Tolva & $24.000 \mathrm{~L}$ & 2 Eje - polietileno
\end{tabular}

Fuente: Stara - www.stara.com.br

Según el sítio de la empresa, con la búsqueda constante de la tecnología y la innovación, Stara consiguió el liderazgo en el mercado de Tolvas. Sus máquinas tienen lo que es más moderno e innovador. Varios accesorios componen las máquinas que se producen todos los días.

En cuanto a la competencia con la IBL, podemos decir que no es un competidor directo. Sus máquinas están en otro rango de precios y recurren a un público determinado, que paga principalmente tener un producto con la marca Stara.

\subsection{Análisis de la competencia}

Teniendo en cuenta la información recopilada, se puede ver que hay muchas opciones de tolvas en el mercado. Todos estos modelos fueron diseñados para satisfacer las diversas necesidades de los agricultores. Hay máquinas de diferentes tamaños, precios y tecnologías.

Teniendo en cuenta el mercado objetivo de este estudio, se puede señalar que la industria local no es suficiente para afectar los negocios de la IBL en Paraguay. Por otro lado, la industria brasileña, y principalmente Argentina, han sido responsables por una mayor competencia. 
Las máquinas argentinas tienen alta calidad y amplia gama de accesorios, por esa razón los agricultores paraguayos no dudan en pagar más para tener una máquina que satisfaga sus necesidades. Más allá de este hecho, las tolvas argentinas tienen tamaños muy grandes, elemento que ha sido necesario para aumentar la productividad de los cultivos de Paraguay.

A su vez, los competidores brasileños entran cada vez más profundamente en el mercado paraguayo, especialmente Stara. Esta tiene diferentes máquinas y apuesta mucho en la tecnología y la innovación, por lo que sus productos tienen un valor más alto y las ventas se basan en la marca y en la diferenciación.

El posicionamiento de la Industrial Busse ante la competencia es seguir poniendo a disposición de los agricultores máquinas de calidad con un precio justo, que es tener productos con la mejor relación costo / beneficio en comparación con los demás. El tema principal de la competencia es que los productores paraguayos buscan máquinas con mayor capacidad, más accesorios y mejor tecnología. Como el foco de IBL es clientes pequeños y medianos, no es posible competir. 


\section{8 - ANÁLISIS SWOT (Strengths, Weaknesses, Opportunities and Threats) (FODA Fortalezas, Oportunidades, Debilidades, Amenazas)}

Para analizar las fortalezas, debilidades, oportunidades y amenazas de la organización, así como el grado de relevancia de cada uno de estos aspectos, este capítulo incluirá un análisis SWOT (FODA). La evaluación de los datos es una escala de 0 a 10, donde las amenazas, así como los puntos débiles que van de 0 a 4 , donde el más relevante sea la amenaza o debilidad, menor será su puntaje, o más cerca de 0 . Por otro lado, las oportunidades y fortalezas siguen el orden inverso, es decir, cuanto mayor es la relevancia, mayor será la puntuación, que van desde 6 a 10, en el que para el punto se usará la nota 5 .

Evaluación de las fortalezas de la Industrial Busse Ltda.

Cuadro 5: Evaluación de los puntos fuertes

\begin{tabular}{|l|c|}
\hline \multicolumn{2}{|c|}{ Evaluación de las fortalezas de la IBL } \\
\hline Fortalezas & $\begin{array}{c}\text { Evaluación } \\
\text { (6 a 10) }\end{array}$ \\
\hline Producto de Calidad & 9 \\
\hline Experiencia en la producción de tolvas & 10 \\
\hline Las tolvas IBL están adaptadas al mercado paraguayo & 8 \\
\hline Prospecto de la máquina en español & 6 \\
\hline Instalaciones modernas & 7 \\
\hline Plazos flexibles de pago & 7 \\
\hline Trayectoria de éxito en las ventas a Paraguay & 9 \\
\hline Solidez de la empresa & 8 \\
\hline Máquinas con excelente relación costo/beneficio & 10 \\
\hline Visión de expansión & 9 \\
\hline Trabajo en conjunto con el importador paraguayo & 8 \\
\hline Calificación de los empleados en general & 9 \\
\hline Lanzamiento inminente de la tolva ABA 12500 multiuso & 10 \\
\hline
\end{tabular}

Fuente: Base de datos de las empresas IBL y Tracto Agovial 
Evaluación de las debilidades de la Industrial Busse Ltda.

Cuadro 6: Evolución de los puntos débiles

\begin{tabular}{|l|c|}
\hline \multicolumn{2}{|c|}{ Evaluación de las debilidades de la IBL } \\
\hline Debilidades & $\begin{array}{c}\text { Evaluación } \\
\mathbf{( 0} \text { a 4) }\end{array}$ \\
\hline Máquinas con pocos accesorios & 1 \\
\hline Máquinas con tamaño inferior al exigido por el mercado & 1 \\
\hline Las tolvas no poseen manual en español & 4 \\
\hline Largo plazo de entrega & 3 \\
\hline La falta de un profesional específico para el servicio de la exportación & 2 \\
\hline Discapacidad de la empresa al mercado exterior & 1 \\
\hline Falta de acciones para promover la venta en el extranjero & 1 \\
\hline Falta de estudio de mercado & 2 \\
\hline Pocas inversiones en nuevas tecnologías & 2 \\
\hline Falta de divulgación de la marca IBL en el mercado paraguayo & 1 \\
\hline Poca participación en ferias & 2 \\
\hline Post-venta poco trabajado & 3 \\
\hline
\end{tabular}

Fuente: Base de datos de las empresas IBL y Tracto Agrovial

Evaluación de las oportunidades encontradas por la Industrial Busse Ltda.

Cuadro 7: Evaluación de las oportunidades

\begin{tabular}{|l|c|}
\hline \multicolumn{2}{|c|}{ Evaluación de las oportunidades encontradas por la IBL } \\
\hline Oportunidades & $\begin{array}{c}\text { Evaluación } \\
(6 \mathbf{a} \mathbf{0})\end{array}$ \\
\hline Aumento de la demanda por tolvas en el Paraguay & 10 \\
\hline Clientes demandan calidad & 9 \\
\hline Clientes dispuestos a pagar más por la satisfacción de necesidades & 9 \\
\hline Ferias agrícolas en el Paraguay & 8 \\
\hline Excelente relación de la empresa con los importadores & 8 \\
\hline Buenas perspectivas para el lanzamiento del ABA 12500 Multiuso & 10 \\
\hline Oportunidades para divulgar máquinas en días de campo & 8 \\
\hline Franco crecimiento de la producción de granos en Paraguay & 9 \\
\hline Capacidad para aumentar las áreas de cultivo & 7 \\
\hline Brasil es uno de los países que más vende máquinas al Paraguay & 7 \\
\hline
\end{tabular}

Fuente: Base de datos de las empresas IBL y Tracto Agrovial 
Evaluación de las amenazas enfrentadas por la Industrial Busse Ltda

Cuadro 8: Evaluación de las amenazas enfrentadas

\begin{tabular}{|l|c|}
\hline \multicolumn{2}{|c|}{ Evaluación de las amenazas enfrentadas por la IBL } \\
\hline Amenazas & $\begin{array}{c}\text { Evaluación } \\
\text { (0 a 4) }\end{array}$ \\
\hline Competidores muy bien cualificados & 1 \\
\hline Mayor número de opciones de máquinas de los competidores & 3 \\
\hline Falta de divulgación de la marca IBL en el Paraguay & 3 \\
\hline Máquinas argentinas muy bien aceptadas por los paraguayos & 2 \\
\hline Máquinas de los competidores ofrecen más accesorios y fuerza & 3 \\
\hline Aumento de grandes propiedades rurales & 2 \\
\hline Reducción del número de pequeños y medios productores & 2 \\
\hline Los clientes buscan novedades & 3 \\
\hline $\begin{array}{l}\text { La apreciación de la moneda brasileña frente al dólar, lo que hace subir } \\
\text { el precio internacional de las máquinas }\end{array}$ & 1 \\
\hline Pérdida de negocios por entrega fuera del plazo acordado & 2 \\
\hline Aparición de empresas procedentes de fusiones y adquisiciones & 3 \\
\hline
\end{tabular}

Fuente: Base de datos de las empresas IBL y Tracto Agovial

\section{9 - ANALISIS ARCO (Aspiraciones de los líderes, Restriciones ambientales, Capacidades de la organización y Oportunidades de negócios)}

En este punto del trabajo se hará el análisis ARCO, para que se pueda direccionar mejor las acciones del análisis FODA. Con esta combinación se espera poder sacar dudas que el FODA no cumple.

\subsection{Aspiraciones de los líderes de la firma}

La empresa Industrial Busse Ltda ya esta hace 40 años en el mercado de máquinas e implementos agrícolas. En todo este tiempo ocurrieron muchas transformaciones, en los productos y en los mercados. Siendo el mercado agrícola muy inestable se tiene que tener en mente que varias dificultades pueden ocurrir. Con eso los líderes de la empresa proyectan un crecimiento gradual y siempre seguro. La empresa pretende adquirir máquinas más modernas para agilizar la producción y 
reducir los costos. La compañía cree que con la renovación de la industria manufacturera, la inversión en ingeniería de fabricación, P\&D (pesquisa e desarrollo) y la inversión en la capacitación de la gente hará posible cumplir satisfactoriamente el mercado nacional y ampliar su mercado externo, y poder alcanzar con seguridad el $10 \%$ de las ventas totales a partir de los mercados externos.

\subsection{Restricciones del negocio}

Hoy, la Industrial Busse Ltda tiene como principal dificultad la capacidad productiva deficiente. Es necesaria una reformulación de los procesos productivos. Muchas cosas ya fueron hechas, pero falta mucho aún para cambiar. En el comienzo de 2013 la empresa tuvo un cuello de botella en la producción donde fue posible ver que muchos aspectos estaban errados y que por lo mismo, que aunque tuvieran ventas no sería posible cumplir con los plazos de entrega que llegaron hasta 60 días. Con la capacidad de producción reducida, y teniendo el mercado brasileño como destino principal, las exportaciones se quedan en segundo plano.

Otra dificultad encontrada por la empresa es la mano de obra especializada. En la región donde la empresa se localiza no se encuentran técnicos para determinadas áreas como por ejemplo soldadura. Por lo tanto no se consigue ampliar la línea de ensamble y con ello tampoco se consigue reducir su plazo de entrega.

\subsection{Capacidades de la organización}

La empresa está muy bien soportada por una condición financiera favorable. Existen varias líneas de crédito disponibles para adquisición de máquinas y equipamientos. Con estas adquisiciones la empresa puede agilizar algunos procesos internos.

Un punto fuerte de la empresa son los empleados motivados. De esta forma se torna más fácil proponer cambios en la producción.

La empresa viene a lo largo de varios años ampliando sus clientes y la preferencia por la marca. Esto es porque la empresa busca siempre la satisfacción de las necesidades de los clientes, con eso se consigue una preferencia cada vez mayor por parte de los mismos. 


\subsection{Oportunidades de negocios}

En los últimos años, la economía brasileña viene creciendo mucho, el mercado agrícola también sigue este camino. Con mucho apoyo del gobierno, principalmente los pequeños y medianos agricultores conseguirán acceso a las líneas de crédito y conseguirán comprar máquinas e implementos.

Con este panorama la Industrial Busse Ltda está encontrando cada vez más oportunidades para crecer en este sector. El desarrollo de nuevas tecnologías y la búsqueda constante hace que también el mercado exterior sea un mercado target para IBL. La participación en ruedas de negocios, la divulgación de los productos en la internet y los contactos hechos en ferias, han aumentado las consultas de cotización de precios y demanda de productos.

La empresa considera que las oportunidades crecerán más en los próximos meses y por eso se está preparando para este crecimiento.

\section{0 - SEGMENTACIÓN, POSICIONAMIENTO Y OBJETIVOS DE MARKETING}

Los siguientes son los segmentos de explotación definidos por IBL, declaración de posicionamiento de la empresa y los objetivos de marketing para el mercado paraguayo.

\subsection{Segmentación}

Inicialmente se debe tener en cuenta que el mercado objetivo de IBL son pequeños y medianos agricultores.

En relación con la segmentación por comportamiento y beneficios, se debe tener en cuenta que las tolvas IBL sirven para todos los tipos de granos. De esta manera se puede definir el mercado objetivo como todos los pequeños y medianos agricultores que producen granos en general. 


\subsection{Posicionamiento}

A raíz del estudio mediante el análisis de los factores internos y externos que implican la empresa, la definición de mercado objetivo y siendo consciente de las aspiraciones de los líderes de la empresa, se debe en este momento definir el posicionamiento más adecuado para la empresa Busse Industrial Ltda. Se sabe que la empresa busca una mayor cuota del mercado de tolvas, crecimiento de la preferencia por la marca IBL en Paraguay, y que la empresa adopte el lema "Calidad al mejor precio disponible para todos."

\subsection{Objetivos del marketing}

Ya dado el posicionamiento al que apunta la compañía ahora se debe definir cuáles son los objetivos del marketing, tanto a corto como a largo plazo. Enlazar la política de producto, la política de precio, la política de comunicación, la política de distribución y la política de servicios de postventa, es el objetivo del mix de marketing.

\subsubsection{Objetivos del producto}

a) Establecer la preferencia de los clientes en cada región del Paraguay por diferentes modelos? de tolvas IBL hasta mediados de 2014;

b) Adaptar al máximo los modelos a las necesidades de los clientes, hasta finales de 2014;

c) Añadir accesorios a los modelos existentes hasta finales de 2014;

d) Lanzar el modelo ABA 12500 multiuso hasta mediados de 2014;

e) Aumento del volumen de ventas de tolvas IBL para el Paraguay: 15\% en $2014,25 \%$ en 2015 y $35 \%$ en 2016. 


\subsubsection{Objetivos de precio}

Mantener siempre el precio justo proporcionando siempre la mejor relación costo/beneficio en comparación con las máquinas del mismo porte presentadas por los competidores.

\subsubsection{Objetivos de promoción}

a) Divulgar la marca IBL en mayor medida en todas las regiones productoras de granos hasta finales de 2015;

b) Mapear el perfil de los consumidores paraguayos y monitorear las necesidades y la satisfacción acerca de las tolvas IBL;

c) El uso de diversos medios de comunicación cómo periódicos, internet, folletos, revistas.

\subsubsection{Objetivos de la distribución}

a) Introducir cada vez más tolvas IBL en reventas del principal importador de Paraguay hasta mediados de 2016;

b) Agilizar el movimiento interno de máquinas de una región a otra del país;

c) Reducir los costos logísticos de transporte internacional.

\subsubsection{Objetivos de servicio al cliente}

a) Capacitar al importador para que pueda proporcionar servicios, aclarar las dudas de los clientes, realizar visitas periódicas después de las ventas;

b) Agilizar la comunicación entre importador y empresa con el objetivo de resolver problemas, quejas y consultas de los clientes finales;

c) Capacitar profesionales del área de exportación para actuaren en el mercado paraguayo. 


\section{1 - ESTRATEGIAS DE MARKETING}

Determinados los objetivos, se debe ahora definir de que forma la Industrial Busse Ltda. los logrará. Así se crearon tres tipos de estrategias basadas en el análisis SWOT (FODA) de los datos.

\subsection{Estrategias de utilización de las capacidades}

Cuadro 9: oportunidades + puntos fuertes $=$ estrategias

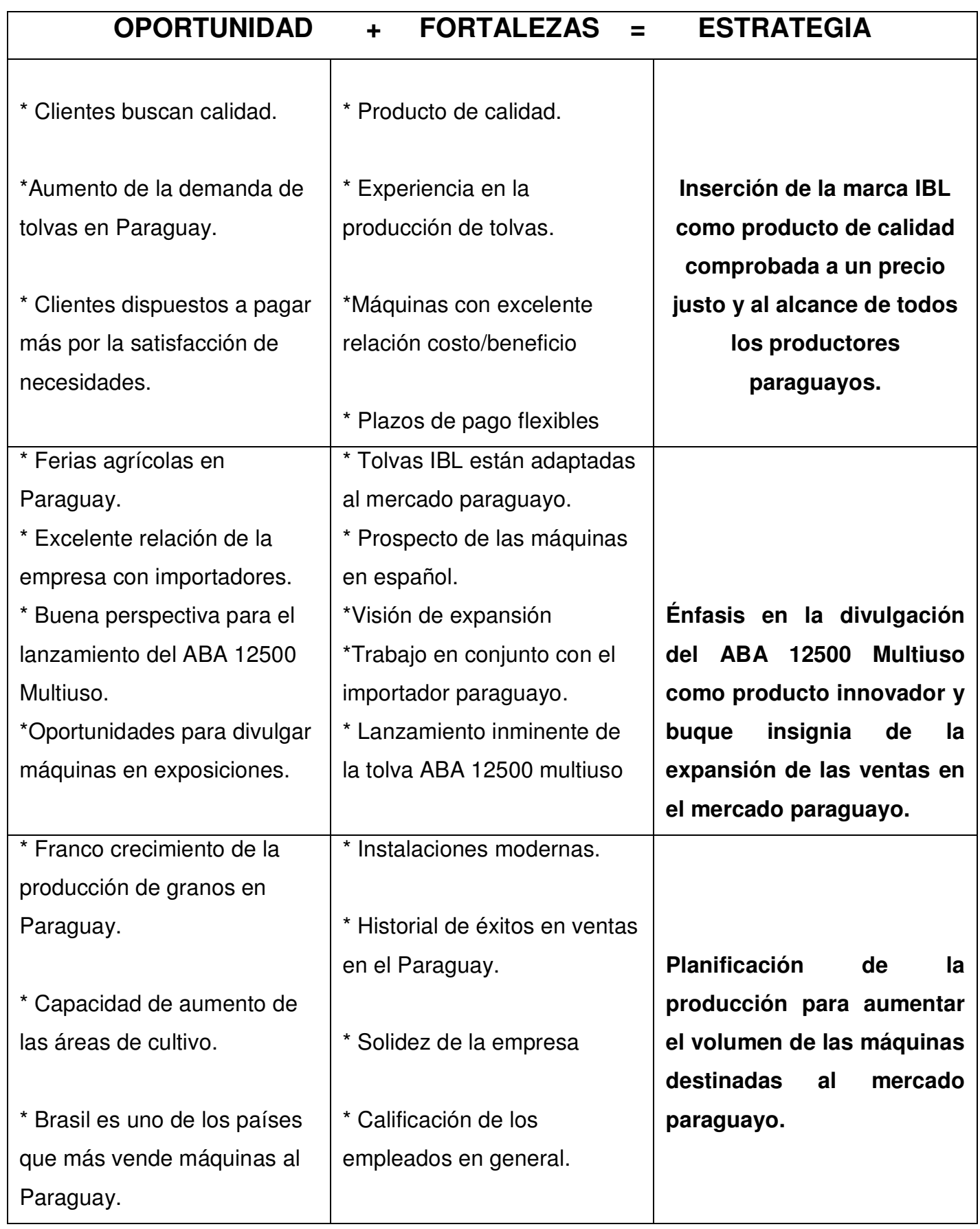




\subsection{Estrategias de minimización de las limitaciones}

Analizando las oportunidades y debilidades de la empresa, tenemos las estrategias de minimización de las limitaciones.

Cuadro 10: oportunidades + puntos flacos = estrategias

\begin{tabular}{|c|c|c|}
\hline OPORTUNIDAD & DEBILIDADES & ESTRATEGIA \\
\hline 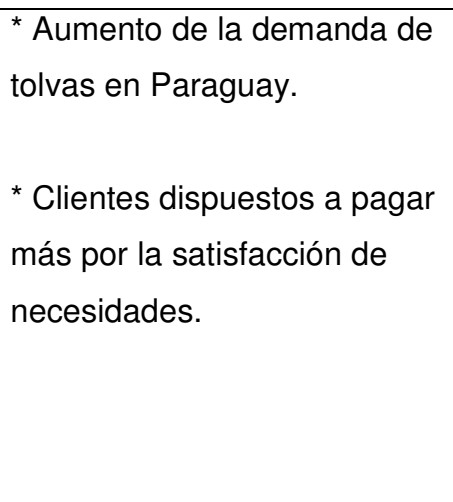 & $\begin{array}{l}{ }^{*} \text { Máquinas con pocos } \\
\text { accesorios } \\
{ }^{*} \text { Poca inversión en nuevas } \\
\text { tecnologías } \\
\text { * Máquinas con tamaño } \\
\text { inferior al exigido por el } \\
\text { mercado. }\end{array}$ & $\begin{array}{l}\text { Posicionar el producto } \\
\text { como de alta calidad y con } \\
\text { la mejor relación costo / } \\
\text { beneficio del mercado }\end{array}$ \\
\hline $\begin{array}{l}\text { * Franco crecimiento de la } \\
\text { producción de granos en } \\
\text { Paraguay. } \\
{ }^{*} \text { Capacidad de aumento de } \\
\text { las áreas de cultivo. } \\
\text { * Brasil es uno de los países } \\
\text { que más vende máquinas al } \\
\text { Paraguay. }\end{array}$ & $\begin{array}{l}{ }^{*} \text { Falta de estudio de } \\
\text { mercado } \\
\text { * Deficiencia de la empresa } \\
\text { para con el mercado exterior. } \\
{ }^{*} \text { Tiempos de entrega } \\
\text { extensos }\end{array}$ & $\begin{array}{c}\text { Reajustar el enfoque de la } \\
\text { empresa hacia el mercado } \\
\text { exterior más seriamente }\end{array}$ \\
\hline $\begin{array}{l}\text { * Ferias agrícolas en } \\
\text { Paraguay. } \\
\text { * Excelente relación de la } \\
\text { empresa con importadores. } \\
\text { * Buena perspectiva para el } \\
\text { lanzamiento del ABA } 12500 \\
\text { Multiuso. } \\
\text { * Oportunidades para divulgar } \\
\text { máquinas en exposiciones. }\end{array}$ & $\begin{array}{l}\text { * La falta de un profesional } \\
\text { específico para el servicio de } \\
\text { la exportación. } \\
\text { * Falta de acciones para } \\
\text { promover la venta en el } \\
\text { extranjero. } \\
\text { * Falta de divulgación de la } \\
\text { marca IBL en el mercado } \\
\text { paraguayo. } \\
\text { * Poca participación en ferias. } \\
\text { * Post-venta poco trabajado }\end{array}$ & $\begin{array}{c}\text { Definición de un } \\
\text { profesional para atender } \\
\text { específicamente el área de } \\
\text { exportación de la empresa } \\
\text { promoviendo acciones y } \\
\text { difusión de la misma en el } \\
\text { extranjero. }\end{array}$ \\
\hline
\end{tabular}




\subsection{Estrategias de conversión de las desventajas}

Cuadro 11: amenazas + puntos flacos $=$ estrategias

\begin{tabular}{|c|c|c|}
\hline $\begin{array}{l}\text { * Competidores muy bien } \\
\text { cualificados }\end{array}$ & $\begin{array}{l}{ }^{*} \text { Máquinas con pocos } \\
\text { accesorios. }\end{array}$ & \\
\hline $\begin{array}{l}{ }^{*} \text { Mayor número de opciones } \\
\text { de máquinas de los } \\
\text { competidores. } \\
\text { * Máquinas de los } \\
\text { competidores ofrecen más } \\
\text { accesorios y fuerza. }\end{array}$ & $\begin{array}{l}\text { * Poca inversión en nuevas } \\
\text { tecnologías } \\
\text { * Máquinas con tamaño } \\
\text { inferior al exigido por el } \\
\text { mercado. }\end{array}$ & $\begin{array}{c}\text { Destacar la alta calidad y la } \\
\text { mejor relación } \\
\text { costo/beneficio }\end{array}$ \\
\hline $\begin{array}{l}\text { * Clientes buscan novedades. } \\
\text { * La sobrevaluación de la } \\
\text { moneda brasileña frente al } \\
\text { dólar, lo que hace subir el } \\
\text { precio internacional de las } \\
\text { máquinas. }\end{array}$ & & \\
\hline $\begin{array}{l}\text { *Aumento de grandes } \\
\text { propiedades rurales. } \\
\text { * Reducción de los pequeños } \\
\text { y medianos productores. } \\
\text { * Falta de divulgación de la } \\
\text { marca IBL en Paraguay. }\end{array}$ & $\begin{array}{l}{ }^{*} \text { Falta de estudio de } \\
\text { mercado } \\
\text { * Deficiencia de la empresa } \\
\text { para con el mercado exterior. }\end{array}$ & $\begin{array}{l}\text { Buscar nuevos mercados, } \\
\text { incluso iniciando } \\
\text { gradualmente la entrada en } \\
\text { las grandes propiedades. }\end{array}$ \\
\hline $\begin{array}{l}\text { * Máquinas argentinas son } \\
\text { muy bien aceptadas por los } \\
\text { paraguayos. } \\
\text { * Pérdida de negocios por } \\
\text { entrega fuera del plazo. } \\
\text { * Aparición de empresas } \\
\text { procedentes de fusiones y } \\
\text { adquisiciones }\end{array}$ & $\begin{array}{l}\text { *Tiempos de entrega } \\
\text { extensos } \\
\text { * Poca participación en ferias. } \\
\text { * Falta de acciones para } \\
\text { promover la venta en el } \\
\text { extranjero. }\end{array}$ & $\begin{array}{l}\text { Remodelar el sector de las } \\
\text { exportaciones y promover } \\
\text { acciones de divulgación en } \\
\text { el mercado paraguayo }\end{array}$ \\
\hline
\end{tabular}




\section{2 - PLANES DE ACCIÓN}

Después de definir los objetivos y las estrategias, es necesario definir cuáles son las acciones para efectuar el plan de marketing. En las páginas siguientes serán definidas las acciones que llevarán al plan de marketing IBL.

12.1 Plan de acción 1 - Aumento de la actuación de la marca IBL en Paraguay

El objetivo de este plan de acción será incrementar la presencia de la marca $\mathrm{IBL}$ en el mercado de maquinaria e implementos agrícolas y analizar la competencia local más de cerca.

Cuadro 12: Plan de accion1

\begin{tabular}{|c|c|c|c|c|}
\hline Acciones & Medidas de desempeño & Responsable & Plazo & Costos \\
\hline $\begin{array}{l}\text { Elaboración de un } \\
\text { calendario anual de ferias } \\
\text { del sector en Paraguay }\end{array}$ & Calendario Creado & Clodovil & $\begin{array}{l}\text { Fin del } \\
\text { año } \\
\text { anterior }\end{array}$ & $\begin{array}{c}\text { Tiempo de } \\
\text { trabajo }\end{array}$ \\
\hline $\begin{array}{l}\text { Definición de la } \\
\text { participación en ferias del } \\
\text { calendario y el costo- } \\
\text { beneficio de dicha } \\
\text { participación }\end{array}$ & Ferias elegidas & Roberto & $\begin{array}{l}\text { Fin del } \\
\text { año } \\
\text { anterior }\end{array}$ & $\begin{array}{l}\text { Las cuotas } \\
\text { de } \\
\text { inscripción } \\
\text { en la feria, } \\
\text { soporte, } \\
\text { envío de } \\
\text { máquinas }\end{array}$ \\
\hline $\begin{array}{l}\text { Análisis y definiciones de } \\
\text { los que van a participar en } \\
\text { ferias }\end{array}$ & $\begin{array}{l}\text { Definición de los } \\
\text { participantes }\end{array}$ & Roberto & $\begin{array}{l}\text { Fin del } \\
\text { año } \\
\text { anterior }\end{array}$ & $\begin{array}{l}\text { Costos de } \\
\text { viaje, } \\
\text { estancia, y } \\
\text { gastos } \\
\text { generales }\end{array}$ \\
\hline $\begin{array}{l}\text { Visitas periódicas del } \\
\text { vendedor IBL para } \\
\text { acompañar el progreso de } \\
\text { las acciones del } \\
\text { importador, visitar clientes } \\
\text { finales y analizar la } \\
\text { competencia. }\end{array}$ & Informe de visitas & Clodovil & $\begin{array}{c}3 \circ 4 \\
\text { veces } \\
\text { por año }\end{array}$ & $\begin{array}{l}\text { Costos de } \\
\text { viaje, } \\
\text { estancia, y } \\
\text { gastos } \\
\text { generales }\end{array}$ \\
\hline
\end{tabular}




\begin{tabular}{|l|c|c|c|c|}
\hline \multicolumn{1}{|c|}{ Acciones } & Medidas de desempeño & Responsable & Plazo & Costos \\
\hline $\begin{array}{l}\text { Comunicación frecuente } \\
\text { con el importador local } \\
\text { para intercambiar ideas } \\
\text { sobre el rendimiento de las } \\
\text { máquinas IBL que ya se } \\
\text { están utilizando en } \\
\text { Paraguay }\end{array}$ & Contacto realizado & $\begin{array}{c}\text { Clodovil, } \\
\text { Patrick }\end{array}$ & Semanal & $\begin{array}{c}\text { Llamadas } \\
\text { telefónicas } \\
\text { y envío de } \\
\text { correos } \\
\text { electrónicos }\end{array}$ \\
\hline $\begin{array}{l}\text { Informar los problemas } \\
\text { que enfrenta el cliente } \\
\text { final en el uso de la } \\
\text { máquina y encontrar } \\
\text { soluciones. }\end{array}$ & $\begin{array}{c}\text { Informe del problema y } \\
\text { definición de una solución } \\
\text { para el mismo }\end{array}$ & $\begin{array}{c}\text { Clodovil, } \\
\text { Patrick }\end{array}$ & $\begin{array}{c}1 \\
\text { semanana } \\
\text { después } \\
\text { del } \\
\text { informe }\end{array}$ & $\begin{array}{l}\text { Tiempo de } \\
\text { trabajo }\end{array}$ \\
\hline
\end{tabular}

12.2 Plan de acción 2 - Enfoque en la divulgación del modelo ABA 12.500

\section{Multiuso}

El objetivo de este plan de acción es difundir el modelo ABA12.500 con mayor intensidad que a las otras tolvas, buscando la introducción de la marca IBL en el mercado paraguayo con cautela, pero consistentemente.

Cuadro 13: Plan de acción 2

\begin{tabular}{|l|c|c|c|c|}
\hline \multicolumn{1}{|c|}{ Acciones } & Medidas de desempeño & Responsable & Plazo & Costos \\
\hline $\begin{array}{l}\text { Hacer disponible el } \\
\text { manual de la máquina } \\
\text { en español }\end{array}$ & $\begin{array}{c}\text { Manual disponible en } \\
\text { español }\end{array}$ & $\begin{array}{c}\text { Ingeniería } \\
\text { Clodovil } \\
\text { Patrick }\end{array}$ & $07 / 2015$ & $\begin{array}{c}\text { Tiempo de } \\
\text { trabajo } \\
\text { Impresión } \\
\text { Gráfica }\end{array}$ \\
\hline $\begin{array}{l}\text { Encaminamiento } \\
\text { periódico de prospectos } \\
\text { de las máquinas y } \\
\text { pequeños regalos al } \\
\text { importador }\end{array}$ & $\begin{array}{c}\text { Recibimiento del material } \\
\text { por la Tracto Agro Vial }\end{array}$ & Clodovil & $\begin{array}{c}\text { Conforme } \\
\text { la } \\
\text { demanda } \\
\text { del } \\
\text { importado } \\
r\end{array}$ & $\begin{array}{c}\text { Prospectos } \\
\text { y regalos } \\
\text { Costo de } \\
\text { envío }\end{array}$ \\
\hline $\begin{array}{l}\text { Tracto Agro Vial } \\
\text { encaminar material de } \\
\text { divulgación para todas } \\
\text { sus filiales }\end{array}$ & $\begin{array}{c}\text { Recibimiento del material } \\
\text { de divulgación por las } \\
\text { filiales }\end{array}$ & Anibal & $\begin{array}{c}09 / 2015 \\
\text { postos } \\
\text { por el }\end{array}$ \\
\hline
\end{tabular}




\subsection{Plan de acción 3 - Encuesta de perfil y nivel de satisfacción con la} IBL

Este plan de acción tiene como objetivo conocer el perfil y las características de los clientes finales paraguayos que han adquirido productos IBL y cuál es su nivel de satisfacción con el producto y los servicios de la IBL y Tracto Agro Vial.

Cuadro 14: Plan de acción 3

\begin{tabular}{|c|c|c|c|c|}
\hline Acciones & Medidas de desempeño & Responsable & Plazo & Costos \\
\hline $\begin{array}{l}\text { Preparación del } \\
\text { cuestionario para su } \\
\text { aplicación a los clientes } \\
\text { IBL actuales en } \\
\text { Paraguay }\end{array}$ & Cuestionario preparado & $\begin{array}{l}\text { Clodovil } \\
\text { Patrick } \\
\text { Roberto }\end{array}$ & 09/2015 & $\begin{array}{l}\text { Tiempo de } \\
\text { trabajo }\end{array}$ \\
\hline $\begin{array}{l}\text { Hacer una prueba de } \\
\text { aplicabilidad con } \\
\text { algunos clientes }\end{array}$ & $\begin{array}{l}\text { Prueba aplicada, cambios } \\
\text { necesarios resaltados. }\end{array}$ & Clodovil & $10 / 2015$ & $\begin{array}{l}\text { Llamadas } \\
\text { telefónicas }\end{array}$ \\
\hline $\begin{array}{l}\text { Realizar las } \\
\text { correcciones necesarias } \\
\text { y establecer el } \\
\text { cuestionario estándar. }\end{array}$ & $\begin{array}{l}\text { Cuestionario estándar listo } \\
\text { para su implementación }\end{array}$ & Clodovil & $10 / 2015$ & $\begin{array}{l}\text { Tiempo de } \\
\text { trabajo }\end{array}$ \\
\hline $\begin{array}{l}\text { Contacto de la Tracto } \\
\text { Agro Vial con el cliente } \\
\text { para informarle acerca } \\
\text { de la entrevista por IBL. }\end{array}$ & $\begin{array}{l}\text { Confirmación por el } \\
\text { importador al cuestionario }\end{array}$ & Anibal & $11 / 2015$ & $\begin{array}{l}\text { Costos } \\
\text { soportados } \\
\text { por el } \\
\text { importador }\end{array}$ \\
\hline $\begin{array}{l}\text { Obtener los datos de } \\
\text { los clientes junto al } \\
\text { importador. }\end{array}$ & Datos recibidos & Clodovil & $11 / 2015$ & $\begin{array}{l}\text { Tiempo de } \\
\text { trabajo }\end{array}$ \\
\hline $\begin{array}{l}\text { Aplicación del } \\
\text { cuestionario a través de } \\
\text { teléfono o correo } \\
\text { electrónico a los } \\
\text { clientes IBL que han } \\
\text { utilizado el producto al } \\
\text { menos } 1 \text { mes. }\end{array}$ & Cuestionario aplicado & $\begin{array}{l}\text { Clodovil } \\
\text { Patrick }\end{array}$ & $\begin{array}{c}12 / 2015 \\
A \\
01 / 2016\end{array}$ & $\begin{array}{l}\text { Llamadas } \\
\text { telefónicas } \\
\text { Envío de } \\
\text { correo } \\
\text { electrónico }\end{array}$ \\
\hline
\end{tabular}




\begin{tabular}{|l|c|c|c|c|}
\hline \multicolumn{1}{|c|}{ Acciones } & Medidas de desempeño & Responsable & Plazo & Costos \\
\hline $\begin{array}{l}\text { Análisis de los } \\
\text { resultados de los } \\
\text { primeros cuestionarios } \\
\text { y definir posibles } \\
\text { acciones de mejora en } \\
\text { relación con el } \\
\text { desempeño de la } \\
\text { empresa y el producto }\end{array}$ & $\begin{array}{c}\text { Reunión para analizar los } \\
\text { resultados }\end{array}$ & $\begin{array}{c}\text { Clodovil } \\
\text { Patrick } \\
\text { Roberto } \\
\text { Engenharia }\end{array}$ & $02 / 2016$ & $\begin{array}{c}\text { Tiempo de } \\
\text { Trabajo }\end{array}$ \\
\hline $\begin{array}{l}\text { Realizar encuestas } \\
\text { periódicas cada vez que } \\
\text { se vende una máquina }\end{array}$ & Cuestionarios aplicados & $\begin{array}{c}\text { Clodovil } \\
\text { Patrick }\end{array}$ & $\begin{array}{c}1 \\
\text { mesdespués } \\
\text { de la } \\
\text { compra }\end{array}$ & $\begin{array}{l}\text { Llamadas } \\
\text { telefónicas }\end{array}$ \\
\hline
\end{tabular}

\subsection{Plan de acción 4 - Análisis periódica de la competencia}

El objetivo de este plan de acción es el de proporcionar a la empresa con información sobre la competencia, sus productos, especificaciones técnicas, sus noticias, los precios y las regiones que actúa.

Cuadro 15: Plan de acción 4

\begin{tabular}{|l|c|c|c|c|}
\hline \multicolumn{1}{|c|}{ Acciones } & Medidas de desempeño & Responsable & Plazo & Costos \\
\hline $\begin{array}{l}\text { Consulta mensual al } \\
\text { sitio de los principales } \\
\text { competidores en busca } \\
\text { de información sobre } \\
\text { productos, noticias y } \\
\text { más. }\end{array}$ & Visitas realizadas & Clodovil & $\begin{array}{c}\text { Fin de cada } \\
\text { mes }\end{array}$ & $\begin{array}{c}\text { Tiempo de } \\
\text { trabajo }\end{array}$ \\
\hline $\begin{array}{l}\text { Producir un informe } \\
\text { con los datos } \\
\text { pertinentes de estos } \\
\text { competidores y los } \\
\text { cambios de un mes a } \\
\text { otro. }\end{array}$ & Informe completo & Clodovil & Fin de cada \\
mes & $\begin{array}{c}\text { Tiempo de } \\
\text { trabajo }\end{array}$ \\
\hline $\begin{array}{l}\text { Añadir al informe } \\
\text { informaciones de la } \\
\text { competencia que surge } \\
\text { de otras fuentes. }\end{array}$ & Informe completo & Clodovil & $\begin{array}{c}\text { Fin de cada } \\
\text { mes }\end{array}$ & $\begin{array}{c}\text { Tiempo de } \\
\text { trabajo }\end{array}$ \\
\hline
\end{tabular}




\subsection{Plan de acción 5 -Ajustar los medios de comunicación para el mercado objetivo}

El objetivo de este plan de acción es proporcionar medios interesantes para llegar a los clientes de manera efectiva; buscando por el uso de otros idiomas además del portugués y destacando los productos, las acciones y el área de exportación de IBL.

Cuadro 16: Plan de acción 5

\begin{tabular}{|l|c|c|c|c|}
\hline \multicolumn{1}{|c|}{ Acciones } & Medidas de desempeño & Responsable & Plazo & Costos \\
\hline $\begin{array}{l}\text { Proveer la página web } \\
\text { de la compañía en } \\
\begin{array}{l}\text { Portugués, Inglés y } \\
\text { Español }\end{array}\end{array} \quad$ Sitio actualizado & $\begin{array}{c}\text { Personal de TI } \\
\text { (Tecnologia } \\
\text { de la } \\
\text { información) }\end{array}$ & $07 / 2015$ & $\begin{array}{c}\text { Tiempo de } \\
\text { trabajo }\end{array}$ \\
\hline $\begin{array}{l}\text { Crear un espacio en el } \\
\text { sitio para divulgar el } \\
\text { sector exportador, con } \\
\text { detalles de los } \\
\text { productos, las acciones } \\
\text { tomadas, novedades y } \\
\text { mercados en los que } \\
\text { opera. }\end{array}$ & Espacio creado & Personal de TI & $07 / 2015$ & $\begin{array}{c}\text { Tiempo de } \\
\text { trabajo }\end{array}$ \\
\hline $\begin{array}{l}\text { Proporcionar los } \\
\text { manuales de las } \\
\text { máquinas en inglés y } \\
\text { español }\end{array}$ & $\begin{array}{c}\text { Manuales disponibles en } \\
\text { inglés y español. }\end{array}$ & $\begin{array}{c}\text { Ingeniería } \\
\text { Clodovil } \\
\text { Patrick }\end{array}$ & $10 / 2015$ & $\begin{array}{c}\text { Tiempo de } \\
\text { trabajo }\end{array}$ \\
\hline
\end{tabular}

\subsection{Plan de acción 6 - Cualificación de proveedores}

Este plan tiene como objetivo el trabajo de clasificación con los proveedores actuales y buscar nuevos proveedores para los accesorios necesarios en las tolvas.

Cuadro 17: Plan de acción 6

\begin{tabular}{|l|l|c|c|c|}
\hline \multicolumn{1}{|c|}{ Acciones } & Medidas de desempeño & Responsable & Plazo & Costos \\
\hline $\begin{array}{l}\text { Estudio para añadir } \\
\text { nuevos accesorios a las } \\
\text { tolvas }\end{array}$ & $\begin{array}{l}\text { Modelos y tipos de } \\
\text { accesorios }\end{array}$ & $\begin{array}{c}\text { Ingeniería } \\
\text { Clodovil } \\
\text { Patrick } \\
\text { Roberto }\end{array}$ & $03 / 2015$ & $\begin{array}{c}\text { Tiempo de } \\
\text { trabajo }\end{array}$ \\
\hline
\end{tabular}




\begin{tabular}{|l|l|c|c|c|}
\hline \multicolumn{1}{|c|}{ Acciones } & Medidas de desempeño & Responsable & Plazo & Costos \\
\hline $\begin{array}{l}\text { Cotizaciones de nuevos } \\
\text { accesorios conforme } \\
\text { modelos definidos }\end{array}$ & Informe de cotizaciones & $\begin{array}{l}\text { Sector de } \\
\text { compras }\end{array}$ & $03 / 2015$ & $\begin{array}{c}\text { Tiempo de } \\
\text { trabajo }\end{array}$ \\
\hline $\begin{array}{l}\text { Creación de asociación } \\
\text { con el proveedor que } \\
\text { presentafla mejor } \\
\text { relación costo-beneficio }\end{array}$ & Asosiación establecida & $\begin{array}{l}\text { Sector de } \\
\text { compras }\end{array}$ & $03 / 2015$ & $\begin{array}{c}\text { Tiempo de } \\
\text { trabajo }\end{array}$ \\
\hline
\end{tabular}

\subsection{Plan de acción 7 -Optimización del proceso de producción}

El objetivo de este plan es mapear el proceso de producción con el fin de mejorar los tiempos de producción, control de inventario y aumentar la eficiencia de la producción.

Cuadro 18: Plan de acción 7

\begin{tabular}{|l|c|c|c|c|}
\hline \multicolumn{1}{|c|}{ Acciones } & Medidas de desempeño & Responsable & Plazo & Costos \\
\hline $\begin{array}{l}\text { Estudio del proceso de } \\
\text { producción y sus etapas }\end{array}$ & Estudio finalizado & $\begin{array}{c}\text { Gestión } \\
\text { industrial } \\
\text { junto con PCP }\end{array}$ & $06 / 2015$ & $\begin{array}{c}\text { Tlempo de } \\
\text { trabajo }\end{array}$ \\
\hline $\begin{array}{l}\text { Definición de los } \\
\text { cuellos de botella y } \\
\text { mejoras }\end{array}$ & $\begin{array}{c}\text { Gestión } \\
\text { industrial } \\
\text { Informe indicando los de botella y } \\
\text { mejoras }\end{array}$ & $06 / 2015$ & $\begin{array}{c}\text { Tiempo de } \\
\text { trabajo }\end{array}$ \\
\hline $\begin{array}{l}\text { Análisis del grado de } \\
\text { influencia de los cuellos } \\
\text { de botella y retrasos en } \\
\text { la producción en } \\
\text { relación al área de } \\
\text { exportación }\end{array}$ & $\begin{array}{c}\text { Análisis realizada y } \\
\text { formalizada }\end{array}$ & $\begin{array}{c}\text { Clodovil } \\
\text { Patrick }\end{array}$ & $07 / 2015$ & $\begin{array}{c}\text { Tiempo de } \\
\text { trabajo }\end{array}$ \\
\hline $\begin{array}{l}\text { Monitoreo y asistencia } \\
\text { para hacer mejoras en } \\
\text { el proceso productivo }\end{array}$ & $\begin{array}{c}\text { Participación en reuniones } \\
\text { sobre el proceso }\end{array}$ & $\begin{array}{c}\text { Clodovil } \\
\text { Patrick }\end{array}$ & $09 / 2015$ & Tiempo de \\
trabajo
\end{tabular}




\begin{tabular}{|l|c|c|c|c|}
\hline $\begin{array}{l}\text { de inventario en } \\
\text { relación al área de } \\
\text { exportación }\end{array}$ & formalizada & Patrick & trabajo \\
\hline $\begin{array}{l}\text { Monitoreo y asistencia } \\
\text { en la mejora del control } \\
\text { de inventario }\end{array}$ & $\begin{array}{c}\text { Participación en reuniones } \\
\text { sobre el proceso }\end{array}$ & $\begin{array}{c}\text { Clodovil } \\
\text { Patrick }\end{array}$ & $10 / 2015$ & $\begin{array}{c}\text { Tiempo de } \\
\text { trabajo }\end{array}$ \\
\hline
\end{tabular}

\subsection{Plan de acción 8 - Cualificación de empleados}

Este plan tiene como objetivo calificar los empleados actuales para realizar mejor las tareas inherentes al sector exportador.

Cuadro 19: Plan de acción 8

\begin{tabular}{|l|c|c|c|c|}
\hline \multicolumn{1}{|c|}{ Acciones } & Medidas de desempeño & Responsable & Plazo & Costos \\
\hline $\begin{array}{l}\text { Designación de } \\
\text { profesional específico } \\
\text { para el sector } \\
\text { exportador }\end{array}$ & Designación realizada & $\begin{array}{c}\text { Geréncia e } \\
\text { sector de RH }\end{array}$ & $01 / 2015$ & $\begin{array}{c}\text { Tiempo de } \\
\text { trabajo } \\
\text { Salario }\end{array}$ \\
\hline $\begin{array}{l}\text { Capacitación técnica y } \\
\text { Comercial con enfoque } \\
\text { en la exportación }\end{array}$ & Capacitación realizada & sector de RH & $02 / 2015$ & $\begin{array}{c}\text { Tiempo de } \\
\text { trabajo }\end{array}$ \\
\hline $\begin{array}{l}\text { Delegar tareas } \\
\text { específicas inherentes } \\
\text { al sector de la } \\
\text { exportación y del } \\
\text { mercado paraguayo }\end{array}$ & $\begin{array}{c}\text { Proyectos destinados al } \\
\text { mercado paraguayo }\end{array}$ & Clodovil & $04 / 2015$ & $\begin{array}{c}\text { Tiempo de } \\
\text { trabajo }\end{array}$ \\
\hline
\end{tabular}




\section{3 - IMPLEMENTACIÓN, EVALUACIÓN Y MONITOREO}

La puesta en práctica de planes de acción debe ocurrir de acuerdo a las fechas previstas y los empleados responsables. La comunicación entre todos los niveles y el compromiso de los niveles superiores son críticos para el éxito del trabajo.

La evaluación y control de los planes de acción deben ser realizados periódicamente en las reuniones quincenales del sector de exportación y ésta con otras áreas enlazadas a las acciones establecidas. Con el fin de analizar la evolución del plan es interesante que estas reuniones sean descritas en actas.

En las reuniones, los responsables de cada etapa de los planes deberán presentar el estado actual de los proyectos en curso, las acciones que se están desarrollando y aún por adoptar, además de exponer las previsiones en el logro de los objetivos. Como no existe un gerente específico para la exportación, el gerente de la empresa será responsable de la conducción de las reuniones y por su cumplimiento. Aún durante las reuniones, debe haber un espacio para una nueva evaluación del plan en su conjunto y su readaptación, si es necesario.

\subsection{Sistema de monitoreo}

Cuadro 19: Sistema de Monitoreo

\begin{tabular}{|c|c|c|}
\hline Acciones & Detalles & Responsable \\
\hline $\begin{array}{c}\text { Determinación de las tareas y su } \\
\text { secuencia }\end{array}$ & $\begin{array}{c}\text { Tareas determinadas de acuerdo a los } \\
\text { planes de acción }\end{array}$ & Todos involucrados \\
\hline Planificación & $\begin{array}{c}\text { El responsable es libre para planificar } \\
\text { cada acción por separado con el fin de } \\
\text { Ilegar a la realización de su tarea de la } \\
\text { manera que mejor considerar }\end{array}$ & Responsables \\
\hline \multicolumn{2}{|c|}{ EJECUCIÓN DE LA TAREA } & Responsables \\
\hline
\end{tabular}




\begin{tabular}{|c|c|c|}
\hline Acciones & Detalles & Responsable \\
\hline Informes & $\begin{array}{l}\text { Fotos } \\
\begin{array}{l}\text { Demostrativos de gastos o horas } \\
\text { trabajadas }\end{array} \\
\text { Cuestionarios auxiliares utilizados } \\
\text { Dudas, críticas y sugerencias }\end{array}$ & Responsables \\
\hline \multicolumn{2}{|c|}{ REUNIÓN GENERAL DE EVALUACIÓN } & Todos involucrados \\
\hline \multicolumn{2}{|c|}{$\begin{array}{c}\text { ANÁLISIS DE LOS RESULTADOS DE LA REALIZACIÓN DE CADA ETAPA EN } \\
\text { RELACIÓN AL PLAN GENERAL }\end{array}$} & Todos involucrados \\
\hline
\end{tabular}




\section{4 - CONSIDERACIONES FINALES}

El estudio trató de desarrollar un plan de marketing detallado y conciso para Industrial Busse Ltda en el mercado paraguayo con el fin de proporcionar orientaciones estratégicas y las mejores prácticas para la inserción competente de la compañía en este mercado.

Fue posible gracias al análisis ambiental comprobar las condiciones actuales de la empresa y el escenario en el que se inserta. Se puede ver, básicamente, que Industrial Busse Ltda tiene todavía un camino muy largo por recorrer en cuanto a la ampliación y el éxito de las exportaciones a Paraguay, pero hay condiciones completas para que esto ocurra y que las oportunidades de mercado son prometedoras. Con base en estas referencias, fueron creadas las estrategias de crecimiento, desarrollo y mantenimiento con el fin de orientar las acciones de la empresa, consciente de sus capacidades, dificultades y perspectivas.

Las acciones pueden ser divididas en tres ejes fundamentales: el primero se refiere a la inserción de la marca IBL como un producto de calidad comprobada y precio justo para todos los productores paraguayos, posicionando el producto de forma adecuada y enfocando su calidad. El segundo grupo de acciones se caracteriza por mejoras, adaptaciones y reducción de costos de los componentes a través de la optimización de procesos / control de la producción, la cualificación de los empleados y los proveedores y las inversiones en investigación y desarrollo. El tercer eje está relacionada principalmente con el proceso de comunicación de la empresa con el medio externo: la búsqueda de un mayor conocimiento del cliente y de la competencia, la adecuación de los medios de comunicación, la intensificación y la dirección consciente de esta.

Se espera que las sugerencias y los datos obtenidos en este estudio puedan ser utilizados como base para la discusión y adopción de mejoras para que la Industrial Busse Ltda pueda alcanzar sus metas en relación con Paraguay. Dado que las medidas propuestas sólo pueden ponerse en práctica cuando todos contribuyan al proceso de manera efectiva y los niveles jerárquicos superiores se comprometan con el plan.

Por último, es importante tener en cuenta que otro aspecto es fundamental para el éxito del plan de marketing: revisión y actualización periódica. En vista del 
mercado y el ambiente de la organización están cambiando constantemente, es necesario que el plan sea flexible y cambiante. 


\section{5 - BIBLIOGRAFIA}

AKRON. Productos. Acedido en 21 de marzo de 2013 en http://www.akron.com.ar

ALEKSINK, Néstor e SERGE,Gustavo.(2012). Fundamentos para um Proyecto de Exportación. 2. ed. Osmar D. BuyattiLibreria Editorial. Buenos Aires.

BARSA. Enciclopédia (em português). 31르 ed. São Paulo: Encyclopædia Britannica do Brasil Publicações, 1994. 16 vol. vol. 12. ISBN 85-7042-069-2

BLADEX - Banco Latinoamericano de Comercio Exterior. Dados de Comércio Internacional. Acedido en 20 de febrero de 2013 en http://www.blx.com

CENTRAL DE INTELIGENCIA DE LOS EEUU - Acedido en 12 de junio de 2014 https://www.cia.gov/library/publications/the-world-factbook/geos/pa.html

CHIAVENATO, Idalberto e SAPIRO, Arão. (2010). Planejamento Estratégico, Fundamentos e aplicações. Ed. Campus. Rio de Janeiro.

DALAZEN. Productos. Acedido en 21 e marzo de 2013 en http://www.dalazen.com.py

ENCICLOPEDIA ABRIL (em português). 33aㅡ ed. São Paulo: Abril, 2007. 568-569 p. 1 vol.

ENCICLOPEDIA BARSA (em português). Enciclopédia Britânica do Brasil Publicações. 35ª ed. São Paulo: Abril, 2009. 470-479 p. 4 vol.

FERRELL, OC; HARTLINE, M. D. (2005).Estratégia de Marketing. São Paulo: Pioneira Thomson Learning.

HEMING, Carlos Augusto. (2006).Principais Dificuldades para as Pequenas e Médias Empresas Competirem no Exterior. Dissertação (Mestrado emAdministração) Programa de Pós-Graduação Interinstitucional PPGA/UNIVATES, Porto Alegre.

JAN. Productos. Acedido en 21 e marzo de 2013 en http://www.jan.com.br

KOTLER, Philip e ARMSTRONG Gary.(2007) Princípios de Marketing. Pearson Prentice Hall .São Paulo.

KOTLER, Philip e KELLER Kevin Lane.(2006). Administração de Marketing.Pearson Prentice Hall .São Paulo. 
LOPEZ, José Manoel Cortiñas. (2005). Comércio Exterior Competitivo. 2. ed. São Paulo: Lex Editora.

MINERVINI, Nicola. (2005).O exportador. 4. Ed. São Paulo: Pearson Prentice Hall.

MINISTÉRIO DE LA AGRICULTURA DEL PARAGUAY- Acedido en 20 de junio de 2014 http://www.mag.gov.py/

MONTECOR, Industrias. Productos. Acedido en 20 de marzo de 2013 en http://www.montecor.com.ar

OMC - Organización mundial Del Comercio. Números de las exportaciones Brasileñas. Acedido em 17 de abril de 2013 en http://www.wto.org.br

OURO VERDE. Productos. Acedido en 21 de marzo de 2013 en http://www.ouroverde.com.py

PARIS, José Antonio. Marketing Esencial. (2009). Un Enfoque Latinoamericano. Buenos Aires: Errepar SA.

PRESIDENCIA DE LA REPÚBLICA DEL PARAGUAY - Acedido en 20 de junio de 2014 http://www.presidencia.gov.py/v1/

RICHIGER. Productos. Acedido en 21 de marzo de 2013 en http://www.richiger.com.ar

SCHWEING, Cristine. Monografia da Universidade Federal do Rio grande do Sul. Plano de marketing Sfil. 2007. Porto Alegre - RS - Brasil

SECEX - Secretaria de Comércio Exteriordo Ministério do Desenvolvimento, indústria e Comércio Exterior. Dados de Exportação. Acedido em 20 de abril de 2013 em http://www.mdic.gov.br

SIMERS - Sindicato das Industrias de Máquinas e Implementos Agrícolas do estado do Rio Grande do Sul. Importância do Setor de Máquinas e Implementos Agrícolas. Acedido em 14 de Abril de 2013 em http://www.simers.com.br

STARA. Productos. Acedido en 20 de marzo de 2013 en http://wwwstara.com.br

UMBU. Productos. Acedido en 21 de marzo de 2013 en http://www.umbu.com.ar

WIKIPEDIA - Enciclopedia digital. Dados acerca de Paraguay. Acedido en 10 de marzo de 2013 en http://www.wikipedia.com 


\section{6 - ADJUNTOS}

FOTOS DE LAS MÁQUINAS

Arrozeira AR 90

Busse Agro

Arrozeira AR100

Busse Agro

Arrozeira AR150

Busse Agro
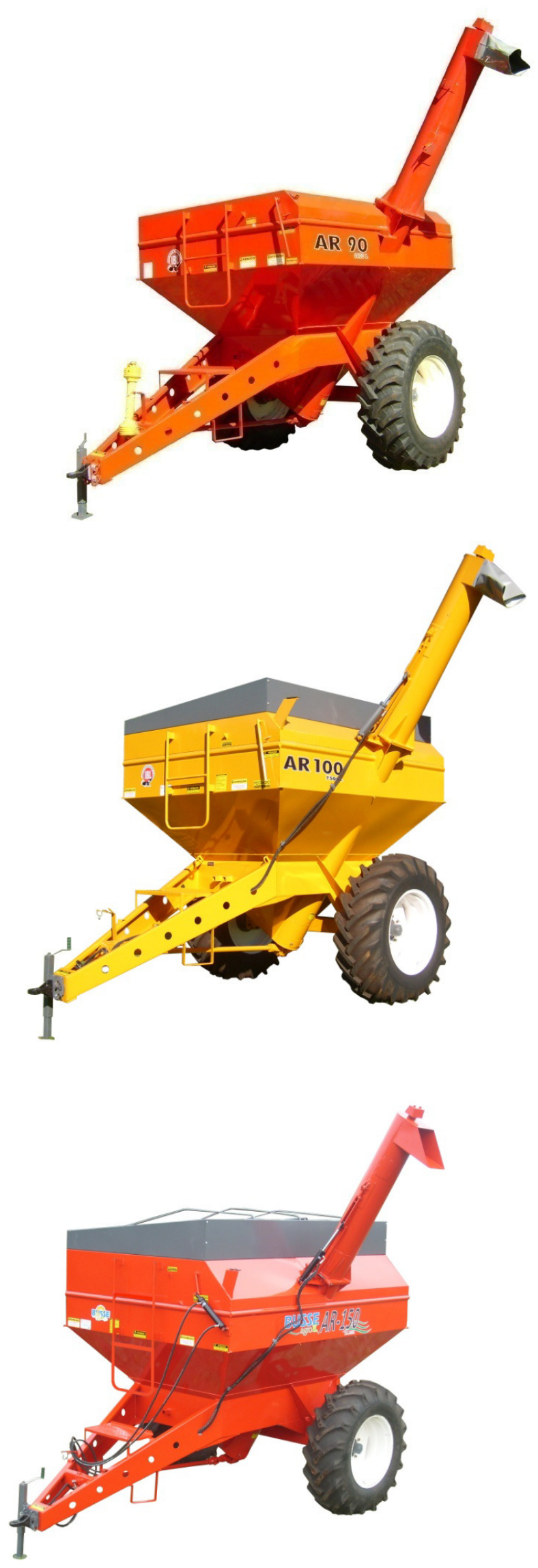


\section{Super Granera 170}

IBL

Super Granera 200

IBL

\section{ABA 12.500 Multiuso}

IBL
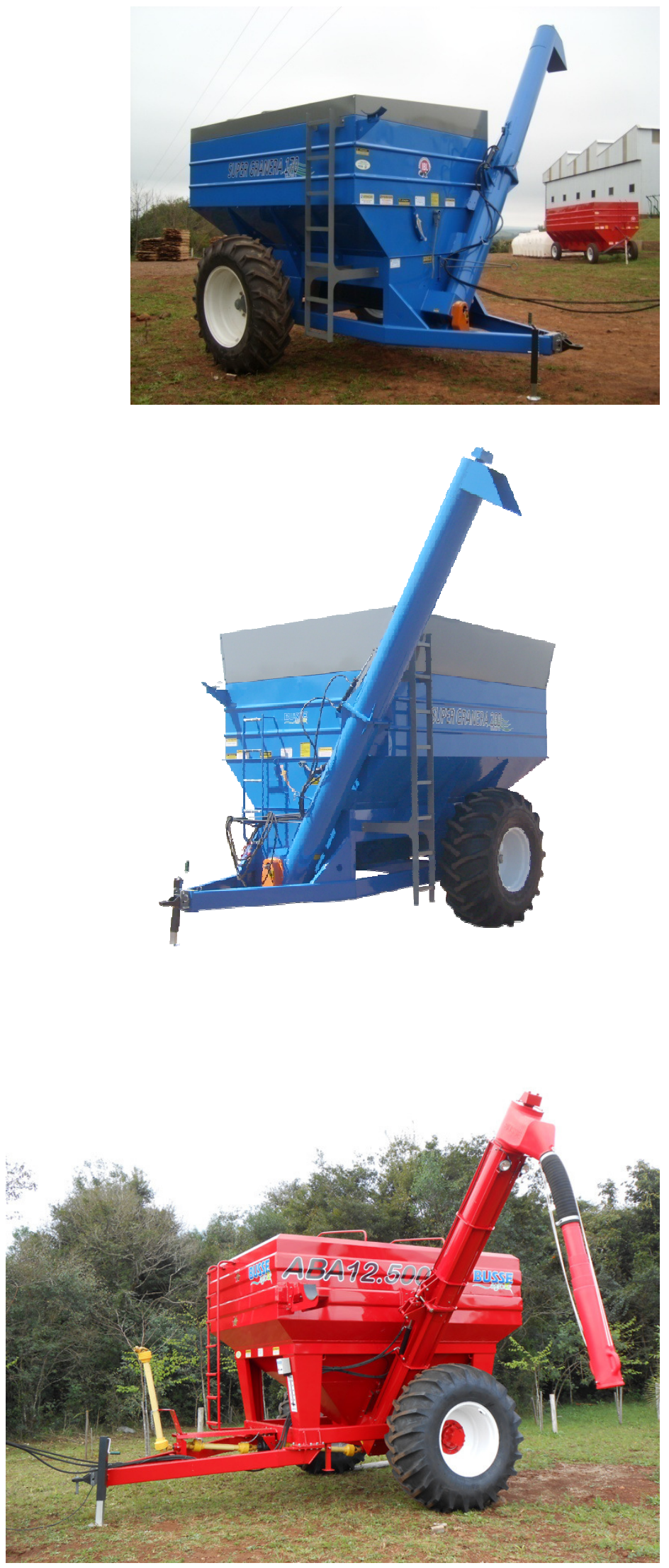
JURAMENTO

"Declaro bajo juramento que esta tesis fue elaborada por mí, que no utilicé ningún otro material que no haya dado a conocer en las referencias y que no utilicé frases o párrafos de otros autores, que este trabajo de !tesis nunca ha sido presentado ante un comité de evaluación de tesis y que no transgreda derechos de terceros."

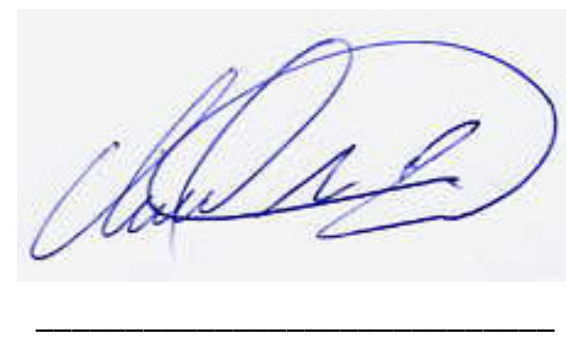

Clodovil Antônio Borghetti 